\title{
Aluminium SHS and RHS subjected to biaxial bending: Experimental testing, modelling and design recommendations
}

\author{
Marina Bock ${ }^{a^{*}}$, Marios Theofanous ${ }^{b}$, Samir Dirar ${ }^{b}$ and Nikolaos Lipitkas ${ }^{b}$ \\ ${ }^{\text {a }}$ School of Architecture and Built Environment, University of Wolverhampton, WV1 1LY, \\ UK \\ ${ }^{\mathrm{b}}$ Department of Civil Engineering, University of Birmingham, B15 2TT, UK
}

\begin{abstract}
Traditionally, experimental research on structural members has focused on the isolated fundamental cases of pure compression/tension, major axis bending or minor axis bending, whilst beam columns under compression and uniaxial bending have also been tested. Biaxial bending has received less experimental attention and it has always been assumed that tests on the idealised cases of major axis bending and minor axis bending can be used together with numerical predictions of biaxial bending to determine suitable interaction curves. This investigation reports an experimental study on aluminium flexural members with variable angles between the plane of bending and the major axis of the cross-section. Cross-sections with various thicknesses and hence plate slenderness values are considered. The experimental results are used to validate a numerical model that allows a large number of cross-sectional dimensions and loading cases to be examined. Following parametric studies and generation of numerical data, the design provisions for biaxial bending specified in EN 1999-1-1 are compared against the predictions provided by the Continuous Strength Method (CSM) and a new proposed method. The comparison shows that EN 1999-1-1 provides overly conservative results with biaxial bending resistances underestimated by approximately $17 \%$. Both the CSM and the proposed method are observed to significantly improve predictions by reducing, on average, underestimations down to $3 \%$ and $1 \%$, respectively, and consequently enabling a better usage of the material and ultimately a more economic and sustainable design.
\end{abstract}

\section{Keywords}

Aluminium, biaxial bending, moment resistance, tubular sections, EN 1999, Continuous Strength Method

\section{Introduction}

Aluminium alloy structural members are lightweight, have high strength-to-weight ratio and high resistance to corrosion, can be shaped into a wide range of cross-sections, whilst being aesthetically pleasant. They are currently used in construction as secondary structural elements in buildings supporting elements of the building envelope as well as in partition walls, windows, doors and staircases among others.

The stress-strain relationship of aluminium alloys exhibits a linear behaviour at low strains becoming rounded with increasing strain while showing strain hardening. Similar to other metals such as cold-formed steel or stainless steel, its material behaviour is therefore 
approximated by a Ramberg-Osgood type law. In the European code for structural aluminium members EN 1999-1-1 [1], aluminium alloys are specified using a numerical designation system with nine possible series followed by a temper designation that indicates the type of heat treatment applied during manufacture. In the built environment, the 6000 and 7000 are the most widely used series which are magnesium-silicon alloys that have a tensile strength $\mathrm{f}_{0}$ of about $300 \mathrm{MPa}$. Compared to steel and due to the fact that aluminium Young modulus E is 70 $\mathrm{GPa}$, aluminium structural components exhibit higher deformations and are more susceptible to buckling.

The advantages of aluminium as a material over other traditional construction materials has led many researchers to investigate the response of aluminium alloy structures under different loading conditions. Existing experimental research on aluminium alloy structures shows that focus has been given to the isolated fundamental cases of tension [2], compression of short [310] and long [9,11-16] columns and uniaxial bending [5,17-25], whilst leaving biaxial bending (i.e. bending about the major and minor axis simultaneously) unexplored.

The treatment of biaxial bending in European design codes has been developed under the assumption that tests on elements under the fundamental cases of minor and major axis bending can be used to calibrate numerical models upon which to base biaxial bending response and subsequent derivation of interaction curves. In the EN 1999-1-1 [1], the design provisions for biaxial bending are found in section 6.2.9 where Eqs. (1-3) should be satisfied.

$\frac{M_{y, E d}}{M_{y, R d}} \leq 1$

$\left(\frac{M_{y, E d}}{M_{y, R d}}\right)^{\gamma_{0}}+\left(\frac{M_{z, E d}}{M_{z, R d}}\right)^{\xi_{0}} \leq 1$

$\left[\left(\frac{M_{y, E d}}{M_{y, R d}}\right)^{1.7}+\left(\frac{M_{z, E d}}{M_{z, R d}}\right)^{1.7}\right]^{0.6} \leq 1$ for hollow or solid cross-sections

In Eqs. (1-3) $M_{y, E d}$ and $M_{z, E d}$ are the design values of the bending moments about the $y-y$ and $\mathrm{z}-\mathrm{z}$ axis respectively, $\mathrm{M}_{\mathrm{y}, \mathrm{Rd}}$ and $\mathrm{M}_{\mathrm{z}, \mathrm{Rd}}$ are the bending moment resistances with respect to the $\mathrm{y}-\mathrm{y}$ and $\mathrm{z}-\mathrm{z}$ axis, and $\gamma_{0}$ and $\xi_{0}$ are defined in Eqs $(4,5)$.

$\gamma_{0}=1$ or alternatively taken as $\alpha_{z}^{2}$ but $1 \leq \gamma_{0} \leq 1.56$

$\xi_{0}=1$ or alternatively taken as $\alpha_{y}^{2}$ but $1 \leq \xi_{0} \leq 1.56$

For the determination of $\mathrm{M}_{\mathrm{y}, \mathrm{Rd}}$ and $\mathrm{M}_{\mathrm{z}, \mathrm{Rd}}$, Eqs $(6,7)$ should be used where $\alpha_{\mathrm{y}}$ and $\alpha_{\mathrm{z}}$ are the shape factors for bending about the $\mathrm{y}$ and $\mathrm{z}$ axis respectively defined in general terms in Table 1. The parameters shown in Table 1 are: $\mathrm{W}_{\mathrm{pl}}$ is the section plastic modulus; $\mathrm{W}_{\mathrm{el}}$ is the section elastic modulus; $W_{\text {eff }}$ is the section effective modulus; $\alpha_{5}$ and $\alpha_{10}$ are shape factors corresponding to curvature values equal to 5 and 10 times the elastic curvature respectively, as defined in Annex G of EN 1999-1-1 [1]; $n$ is the material Ramberg-Osgood exponent in the plastic range; $\beta$ is the slenderness parameter defined in terms of the width-to-thickness ratio of the plated elements of the cross-section and $\beta_{2}$ and $\beta_{3}$ are the Class 2 and Class 3 slenderness limits defined in Table 6.2 of EN 1999-1-1 [1]. The use of the alternative shape factors $\alpha_{5}$ and $\alpha_{10}$ is an alternative approach outlined in Annex F of EN 1999-1-1 that accounts for the material strain hardening. The former factor $\alpha_{5}$ is used for brittle alloys with a strain at ultimate stress 
$\varepsilon_{u}$ between 4 and $8 \%$, while the latter factor $\alpha_{10}$ is used for ductile alloys able to reach a $\varepsilon_{\mathrm{u}}$ greater than $8 \%$.

$M_{y, R d}=\alpha_{y} W_{e l, y} f_{0} / \gamma_{M 1}$
$M_{z, R d}=\alpha_{z} W_{e l, z} f_{0} / \gamma_{M 1}$

Table 1 Shape factors $\alpha[1]$

\begin{tabular}{ll}
\hline $\begin{array}{l}\text { Cross- } \\
\text { section class }\end{array}$ & $\alpha$ \\
\hline 1 & $\alpha_{0}=W_{p l} / W_{e l}$ or \\
& $\alpha_{5}=5-(3.89+0.0019 n) / \alpha_{0}^{(0.270+0.0014 n)}$ \\
& $\alpha_{10}=\alpha_{0}^{(0.21 \log (1000 n))} 10^{\left(7.96 \cdot 10^{-2}-8.09 \cdot 10^{-2} \log \left(\frac{n}{10}\right)\right)}$ \\
2 & $W_{p l} / W_{e l}$ \\
3 & 1 or $1+\left(\frac{\beta_{3}-\beta}{\beta_{3}-\beta_{2}}\right)\left(\frac{W_{p l}}{W_{e l}}\right)$ \\
4 & $W_{e f f} / W_{e l}$
\end{tabular}

An alternative design method that accounts for material strain hardening and therefore can be also used to determine the cross-sectional bending resistances is the continuous strength method (CSM). The development of the CSM started in early 2000s when the method was first developed for predicting compression and bending resistances in isolation of stainless steel austenitic sections [26]. Subsequently, the method was extended to cover other stainless steel alloys $[27,28]$, conventional structural steel also under combined compression and uniaxial bending $[29,30]$ as well as aluminium alloys $[21,31]$. The CSM is currently included in the AISC Design Guide 30 [32] and has two main components: (1) the base curve that establishes the deformation that a cross-section can achieve and (2) a material model that allows for strain hardening. For the above mentioned materials, the CSM has been developed for square hollow sections (SHS), rectangular hollow sections (RHS) and I-sections. Its applicability to biaxial bending design has not been considered which will be investigated in the present article.

The CSM base curve gives the normalised deformation cross-section capacity $\varepsilon_{\mathrm{csm}} / \varepsilon_{\mathrm{y}}$, where $\varepsilon_{\mathrm{y}}=\mathrm{f}_{0} / \mathrm{E}$ is the material yield strain, as a continuous function of the cross-section slenderness $\bar{\lambda}_{p}$ as given by Eq. (14). The normalised deformation capacity $\varepsilon_{\mathrm{csm}} / \varepsilon_{\mathrm{y}}$ is limited to the minimum of either 15 or $\mathrm{C}_{1} \varepsilon_{\mathrm{u}} / \varepsilon_{\mathrm{y}}$, where $\varepsilon_{\mathrm{u}}$ is the strain at the ultimate stress of the material. The first limitation relates to the material ductility requirements set out in EN 1993-1-1 [33] while the second limitation avoids over-predictions associated with the material model. A value for $\mathrm{C}_{1}=0.5$ is used for aluminum alloys. The base curve applies to stocky sections with a $\bar{\lambda}_{p} \leq 0.68$ [27] determined as given by Eq. (15) where $\sigma_{\mathrm{cr}}$ (or $\mathrm{M}_{\mathrm{cr}}$ ) is the elastic buckling stress (or critical bending moment) of either the full cross-section or its most slenderness constituent plate element. The elastic buckling stress (or critical moment) of the full cross-section can be found by either using numerical tools such as the CUFSM [34] or empirical equations [35, 36] while classical analytical expressions for individual plates [37] can be used for determining the elastic buckling stress of the cross-section's most slenderness element. It is worth pointing out that the two former methods account for element interaction effects and consequently provide more favourable results. 


$$
\begin{aligned}
& \frac{\varepsilon_{c s m}}{\varepsilon_{y}}=\frac{0.25}{\bar{\lambda}_{p}^{3.6}} \text { but } \frac{\varepsilon_{c s m}}{\varepsilon_{y}} \leq \min \left(15, \frac{C_{1} \varepsilon_{u}}{\varepsilon_{y}}\right) \\
& \bar{\lambda}_{p}=\sqrt{\frac{f_{0}}{\sigma_{c r}}} \text { for compression and } \bar{\lambda}_{p}=\sqrt{\frac{M_{e l}}{M_{c r}}} \text { for bending }
\end{aligned}
$$

The CSM employs an elastic, linear hardening stress-strain model and allows converting the normalised strain $\varepsilon_{\mathrm{csm}} / \varepsilon_{\mathrm{y}}$ into the CSM stress $\sigma_{\mathrm{csm}}$ as given by Eq. (16) where Esh is the material strain hardening slope given, for aluminium alloys, by Eq. (17). In the determination of Esh, either experimental or material property values given in EN 1999-1-1[1] for the yield strength $f_{0}$ and ultimate stress $f_{u}$ can be used along with a revised equation for the material model for $\varepsilon_{u}$ given in Annex E of EN 1999-1-1 [1] derived in [38] and given in Eq. (18).

$$
\begin{aligned}
\sigma_{c s m} & =f_{0}+E_{s h} \varepsilon_{y}\left(\frac{\varepsilon_{c s m}}{\varepsilon_{y}}-1\right) \\
E_{s h} & =\frac{f_{u}-f_{0}}{0.5 \varepsilon_{u}-\varepsilon_{y}} \\
\varepsilon_{u} & =0.13\left(1-\frac{f_{0}}{f_{u}}\right)+0.059
\end{aligned}
$$

Once the $\sigma_{\mathrm{csm}}$ is found, the cross-sectional compression $\mathrm{N}_{\mathrm{csm}}$ and bending resistances for major axis $\mathbf{M}_{\mathrm{y}, \mathrm{csm}}$ and minor axis bending $\mathbf{M}_{\mathrm{z}, \mathrm{csm}}$ can be determined as shown by Eqs. (19)-(21). In Eq. (21) $\alpha$ is a dimensionless coefficient taken as 2 for SHS/RHS and 1.2 for I-sections.

$$
\begin{aligned}
& N_{c s m}=\sigma_{c s m} A \\
& M_{y, c s m}=W_{p l, y} f_{0}\left[1+\frac{E_{s h}}{E} \frac{W_{e l, y}}{W_{p l, y}}\left(\frac{\varepsilon_{c s m}}{\varepsilon_{y}}-1\right)-\left(1-\frac{W_{e l, y}}{W_{p l, y}}\right) /\left(\frac{\varepsilon_{c s m}}{\varepsilon_{y}}\right)^{2}\right] \\
& M_{z, c s m}=W_{p l, z} f_{0}\left[1+\frac{E_{s h}}{E} \frac{W_{e l, z}}{W_{p l, z}}\left(\frac{\varepsilon_{c s m}}{\varepsilon_{y}}-1\right)-\left(1-\frac{W_{e l, z}}{W_{p l, z}}\right) /\left(\frac{\varepsilon_{c s m}}{\varepsilon_{y}}\right)^{\alpha}\right]
\end{aligned}
$$

Through experimental testing and numerical modelling of aluminium alloy members subjected to the fundamental cases of major and minor axis bending, and biaxial bending (i.e. major and minor axis bending simultaneously), the present article generates structural behaviour data. The main objectives are to assess the accuracy of the above mentioned design methods and propose an alternative approach based on numerical integration. Ultimately, the present article presents recommendations to deal with biaxial bending design. The sections under consideration are extruded square hollow sections (SHS) and rectangular hollow sections (RHS) made of aluminium alloys of the 6000 series.

\section{Experimental study}

\subsection{Geometry of specimens}

Fourteen 4-point bending tests were carried out on four SHS and two RHS beams made of extruded aluminium. The testing took place in the Civil Engineering Laboratory of the University of Birmingham. The nominal dimensions $\mathrm{H} \times \mathrm{B} \times \mathrm{t}$ of the overall high $\mathrm{H}$, overall width $\mathrm{B}$ and thickness as depicted in Figure 1 were $50 \times 50 \times 1.64,50 \times 50 \times 2,50 \times 50 \times 3,50 \times 50 \times 5$, $100 \times 50 \times 3$ and $100 \times 50 \times 6$. The measured dimensions are presented in Table 2 where L is the total length of the specimen. Table 2 also indicates whether the specimen was tested in uniaxial 
or biaxial bending. Note that the uniaxial tests performed on $100 \times 50 \times 3$ and $100 \times 50 \times 6$ are referred to as "major" and "minor" when the specimen was subjected to major or minor axis bending respectively. A total of 8 uniaxial bending and 6 biaxial bending tests were conducted. The specimens were made of the aluminium grades 6063T6, 6060 and $6082 \mathrm{~T} 6$ which for crosssection classification purposes are categorised according to Table 3.2 of EN 1999-1-1 [1] with a buckling class $\mathrm{A}$.

Table 2 Dimensions of the cross-sections

\begin{tabular}{lllcccc}
\hline Cross-section & Test & Mill grade & $\mathrm{H}(\mathrm{mm})$ & $\mathrm{B}(\mathrm{mm})$ & $\mathrm{t}(\mathrm{mm})$ & $\mathrm{L}(\mathrm{mm})$ \\
\hline $50 \times 50 \times 1.64$ & Uniaxial & $6063 \mathrm{~T} 6$ & 51.10 & 51.10 & 1.64 & 995 \\
$50 \times 50 \times 2$ & Uniaxial & 6060 & 49.90 & 49.90 & 1.97 & 995 \\
$50 \times 50 \times 3$ & Uniaxial & 6060 & 50.00 & 50.00 & 3.00 & 995 \\
$50 \times 50 \times 5$ & Uniaxial & $6082 \mathrm{~T} 6$ & 50.10 & 50.10 & 4.75 & 995 \\
$100 \times 50 \times 3$ & Major & $6082 \mathrm{~T} 6$ & 100.10 & 50.00 & 2.93 & 1500 \\
$100 \times 50 \times 3$ & Minor & $6082 \mathrm{~T} 6$ & 100.10 & 50.00 & 2.93 & 1500 \\
$100 \times 50 \times 6$ & Major & $6082 \mathrm{~T} 6$ & 101.60 & 50.80 & 6.00 & 1500 \\
$100 \times 50 \times 6$ & Minor & $6082 \mathrm{~T} 6$ & 101.60 & 50.80 & 6.00 & 1500 \\
$50 \times 50 \times 1.64$ & Biaxial & $6063 \mathrm{~T} 6$ & 50.00 & 50.00 & 1.64 & 995 \\
$50 \times 50 \times 2$ & Biaxial & 6060 & 50.00 & 50.00 & 1.97 & 995 \\
$50 \times 50 \times 3$ & Biaxial & 6060 & 50.00 & 50.00 & 3.00 & 995 \\
$50 \times 50 \times 5$ & Biaxial & $6082 \mathrm{~T} 6$ & 50.00 & 50.00 & 4.85 & 995 \\
$100 \times 50 \times 3$ & Biaxial & $6082 \mathrm{~T} 6$ & 100.00 & 50.00 & 2.93 & 1500 \\
$100 \times 50 \times 6$ & Biaxial & $6082 \mathrm{~T} 6$ & 101.60 & 50.80 & 6.00 & 1500 \\
\hline
\end{tabular}

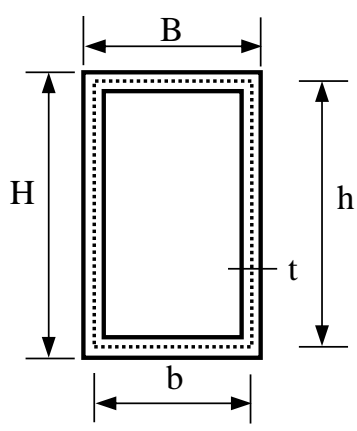

Figure 1 Cross-sectional notation

\subsection{Material properties}

Coupons were extracted from the cross-sections and subsequently tested in a $50 \mathrm{kN}$ Zwick Roell tensile testing machine in accordance with the EN ISO 6892-1:2016 [39]. The coupons were $12.5 \mathrm{~mm}$ wide with a gauge length of $5.65 \sqrt{ } \mathrm{A}$ where $\mathrm{A}$ is the area of the coupon along the gauge length. The coupons were tested under strain control with an applied strain rate of $0.007 \% / \mathrm{s}$ up to the $0.2 \%$ proof strength $\mathrm{f}_{0}$ and then a strain rate of $0.025 \% / \mathrm{s}$ was applied until fracture. A total of eight tensile coupon tests were performed and the obtained material properties are presented in Table 3 where $t$ is the thickness of the coupon, $E$ is the Young's modulus, $\mathrm{f}_{0}$ is the $0.2 \%$ proof strength, $\mathrm{n}$ is the Ramberg-Osgood exponent, $\mathrm{f}_{\mathrm{u}}$ is the ultimate stress and $\varepsilon_{u}$ is the strain at ultimate stress. Figure 2 shows some of the failed coupons while Figure 3 depicts the stress-strain relationship. It is worth pointing out that the revised model for $\varepsilon_{\mathrm{u}}$ developed in [38] and given in Eq. (18) better matched the experimental data presented 
here than the current model given in Annex E of EN 1999-1-1 [1]. The material properties were used to determine the cross-sectional bending resistances and parameters associated with the CSM material model.

Table 3 Tensile coupon test results

\begin{tabular}{lcccccc}
\hline Coupon & $\mathrm{t}(\mathrm{mm})$ & $\mathrm{E}(\mathrm{GPa})$ & $\mathrm{f}_{0}(\mathrm{MPa})$ & $\mathrm{n}$ & $\mathrm{f}_{\mathrm{u}}(\mathrm{MPa})$ & $\varepsilon_{\mathrm{u}}(\%)$ \\
\hline $50 \times 50 \times 1.64-1$ & 1.64 & 66.00 & 219 & 40 & 239 & 6.76 \\
$50 \times 50 \times 1.64-2$ & 1.64 & 66.00 & 207 & 40 & 225 & 6.83 \\
$50 \times 50 \times 2-1$ & 1.97 & 67.20 & 213 & 35 & 235 & 7.34 \\
$50 \times 50 \times 2-2$ & 1.97 & 67.20 & 210 & 35 & 232 & 6.82 \\
$50 \times 50 \times 3-1$ & 3.00 & 67.80 & 208 & 30 & 240 & 7.40 \\
$50 \times 50 \times 3-2$ & 3.00 & 67.30 & 188 & 27 & 218 & 8.36 \\
$50 \times 50 \times 5-1$ & 4.85 & 66.00 & 277 & 55 & 301 & 8.40 \\
$100 \times 50 \times 3-1$ & 2.93 & 66.00 & 300 & 35 & 339 & 8.40 \\
\hline
\end{tabular}

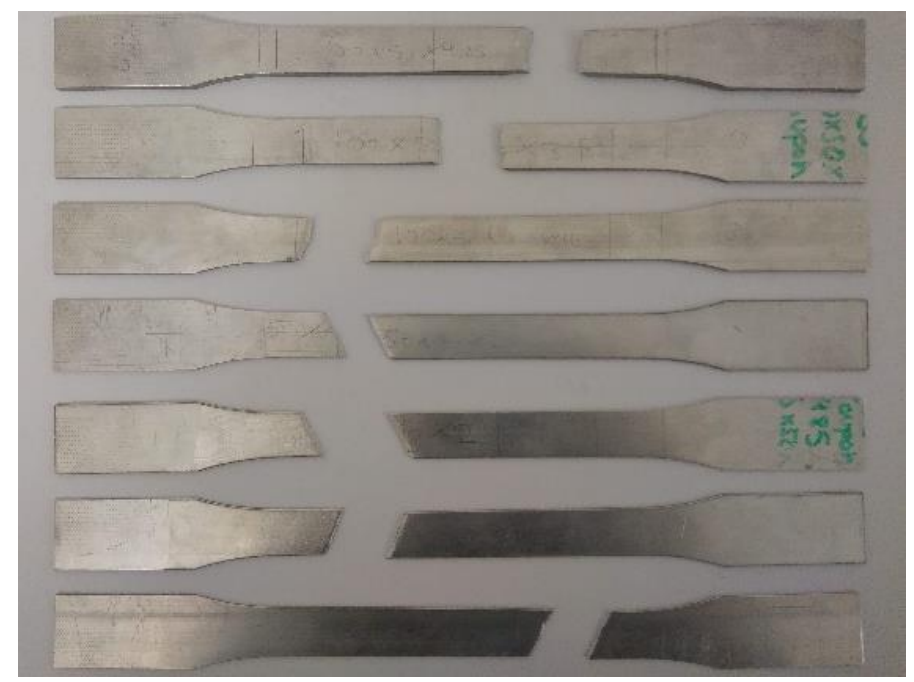

Figure 2 Failed tensile coupons

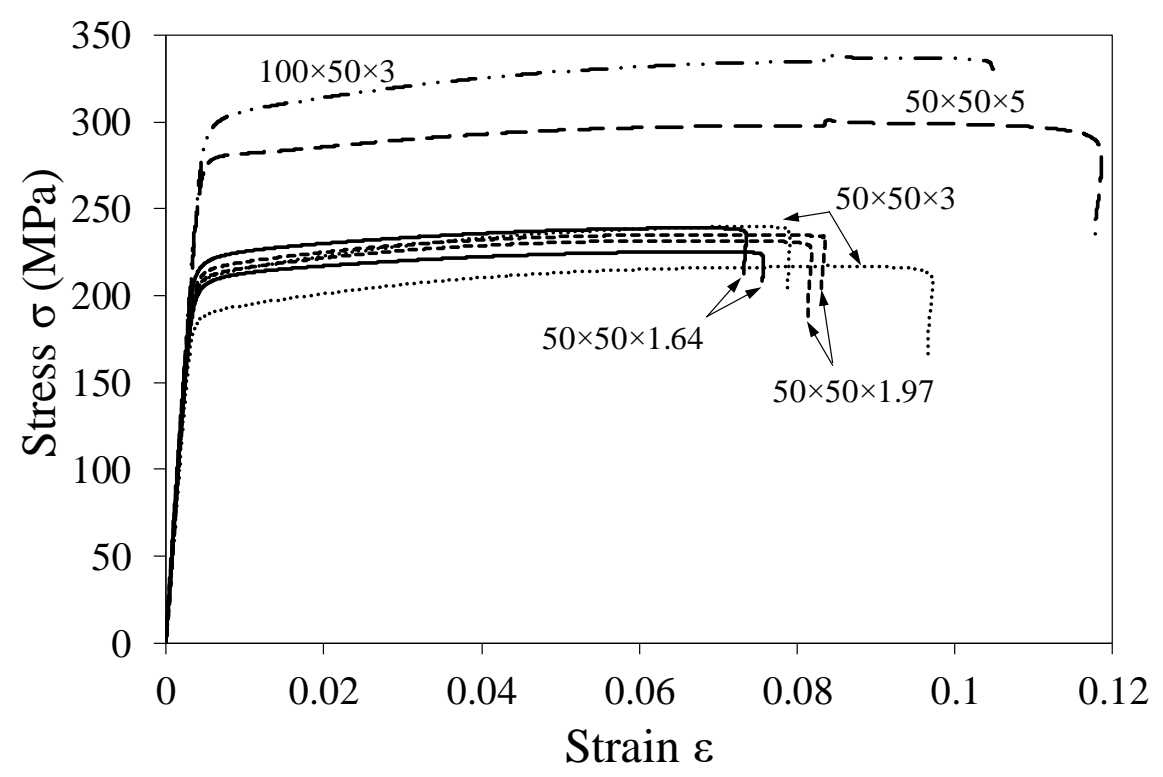

Figure 3 Material stress-strain relationship of the tested coupons 


\subsection{Uniaxial bending tests}

Eight uniaxial bending tests under the 4-point bending configuration were carried out to determine the flexural response of the aluminium alloy members. The SHS $50 \times 50 \times 1.67$, $50 \times 50 \times 2,50 \times 50 \times 3$ and $50 \times 50 \times 5$ were tested about one axis while the RHS $100 \times 50 \times 3$ and RHS $100 \times 50 \times 6$ were tested about both major $(\mathrm{Mj})$ and minor $(\mathrm{Mn})$ axes. All the beams were simply supported with steel rollers and plates that allowed in-plane rotation. The clear span (i.e. distance between support rollers) of the SHS and RHS specimens was $900 \mathrm{~mm}$ and 1400 $\mathrm{mm}$ respectively.

The 4-point loading arrangement was achieved with a spreader beam that transferred the load applied by a $400 \mathrm{kN}$ capacity hydraulic actuator onto the specimens through an arrangement of plates and rollers as depicted in Figure 4. The distance between the points of loading and supports $\mathrm{L}_{0}$ was $300 \mathrm{~mm}$ in the tests on SHS and RHS about the minor axis bending and 600 $\mathrm{mm}$ in the tests on RHS about the major axis bending. Due to the symmetric loading arrangement, a constant bending moment diagram and curvature resulted in the region between the two vertical loads. The load was applied at $1.7 \mathrm{~mm} / \mathrm{min}$ and wooden blocks were inserted at the point loads and supports to prevent web crippling failure [40-42].

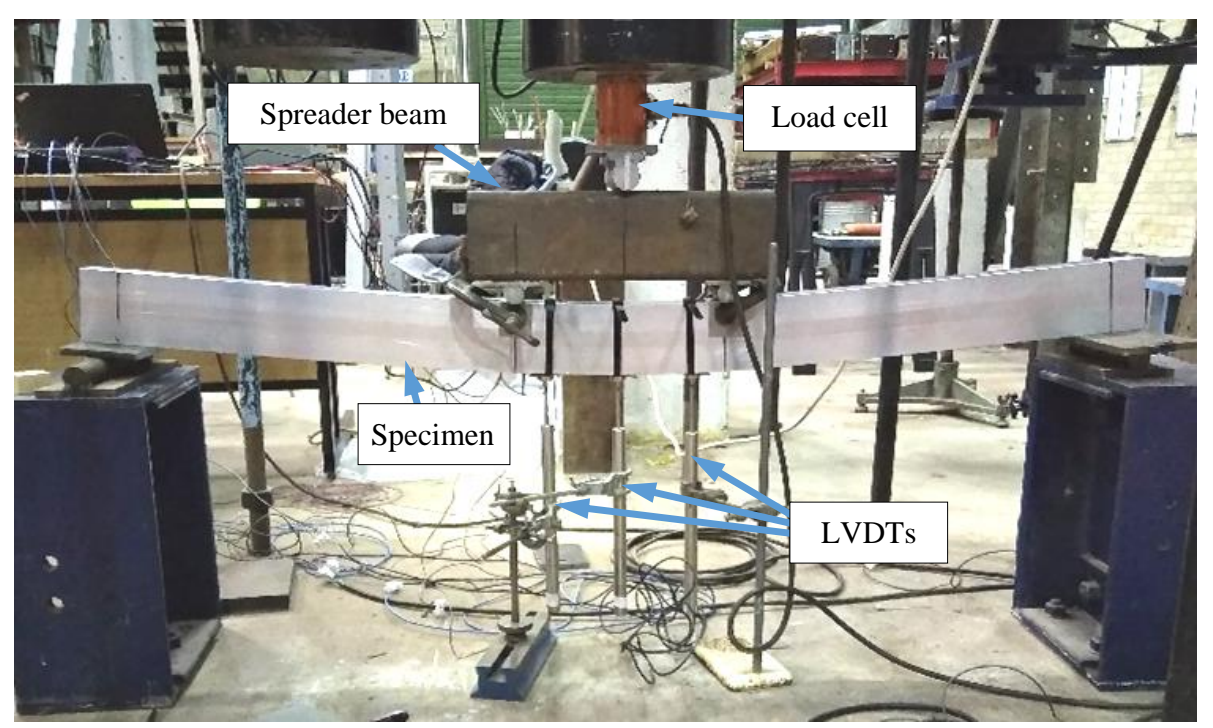

Figure 4 Experimental set up and instrumentation of the uniaxial bending tests

The instrumentation consisted of a load cell, three linear vertical displacement transducers (LVDTs) and strain gauges which were all connected to a data acquisition system model DataTacker DT85. The load cell was placed under the actuator to record the applied load F. The three LVDTs were placed to measure the displacement at midspan ums and the displacement under the loading points $\mathrm{u}_{1}$ and $\mathrm{u}_{2}$. The readings provided by the LVDTs were used to determine the curvature of the beam $\kappa$ as given in Eq. (22) [43] where $u_{a v}$ is the average displacement at the loading points determined as $\mathrm{u}_{\mathrm{av}}=\left(\mathrm{u}_{1}+\mathrm{u}_{2}\right) / 2$ and $\mathrm{Lm}$ is the distance apart of the LVDTs placed under such loading points which was $200 \mathrm{~mm}$ in the tests on SHS and RHS about the major axis bending and $500 \mathrm{~mm}$ in the tests on RHS about the minor axis bending. Strain gauges were affixed at the top (compression) and bottom (tension) flanges at midspan to recode the onset of local buckling, material non-linear effects and a second reading of the 
curvature of the beam. To calculate the latter parameter, the absolute values of strain measured at the top flange were added to the absolute values of strain measured at the bottom flange and divided by the overall height of the section. All the data recorded by the instrumentation was logged at $2 \mathrm{~s}$ intervals.

$\kappa=\frac{8\left(u_{m s}-u_{a v}\right)}{4\left(u_{m s}-u_{a v}\right)^{2}+L_{m}^{2}}$

The acquired data was used to determine the ultimate load $F_{u, e x p}$ and associated moment $M_{u, e x p}$ achieved by the tested specimens as well as the curvature at the ultimate bending moment $\kappa_{\mathrm{u} \text {,exp }}$ given in Table 4. This table also reports other relevant results including the elastic buckling stress $\sigma_{\mathrm{cr}}$ determined by using the CUFSM [34], the slenderness of the full cross-section $\bar{\lambda}_{p}$, the ultimate moment resistance normalised by the plastic moment resistance $\mathrm{M}_{\mathrm{u}, \mathrm{exp}} / \mathrm{M}_{\mathrm{pl}}$ where $\mathrm{M}_{\mathrm{pl}}=\mathrm{W}_{\mathrm{pl}} \cdot \mathrm{f}_{0}$, the plastic curvature $\kappa_{\mathrm{p}}=\mathrm{M}_{\mathrm{p}} / \mathrm{EI}$ and the observed failure mode $(\mathrm{FM})$. There was a problem with one of the LVDTs during the test of $100 \times 50 \times 6-\mathrm{Mn}$ that prevented the experimental curvature from being determined.

Table 4 Results of the uniaxial bending tests

\begin{tabular}{lccccccccc}
\hline Specimen & $\begin{array}{c}\text { Span } \\
(\mathrm{mm})\end{array}$ & $\mathrm{L}_{0}(\mathrm{~mm})$ & $\begin{array}{c}\sigma_{\mathrm{cr}} \\
(\mathrm{MPa})\end{array}$ & $\bar{\lambda}_{p}$ & $\begin{array}{c}\mathrm{M}_{\mathrm{u}, \exp } \\
(\mathrm{KNm})\end{array}$ & $\begin{array}{c}\mathrm{M}_{\mathrm{u}, \exp } / \\
\mathrm{M}_{\mathrm{pl}}\end{array}$ & $\begin{array}{c}\kappa_{\mathrm{u}, \exp } \\
\left(\mathrm{mm}^{-1}\right)\end{array}$ & $\begin{array}{c}\kappa_{\mathrm{u}, \exp } / \\
\kappa_{\mathrm{pl}}\end{array}$ & $\mathrm{FM}$ \\
\hline $50 \times 50 \times 1.64$ & 900 & 300 & 392 & 0.74 & 1.05 & 0.79 & $89 \times 10^{-6}$ & 0.58 & $\mathrm{LB}$ \\
$50 \times 50 \times 2$ & 900 & 300 & 589 & 0.59 & 1.24 & 0.82 & $168 \times 10^{-6}$ & 1.08 & $\mathrm{LB}$ \\
$50 \times 50 \times 3$ & 900 & 300 & 1393 & 0.39 & 2.07 & 0.97 & $1116 \times 10^{-6}$ & 8.62 & $\mathrm{Y}$ \\
$50 \times 50 \times 5$ & 900 & 300 & 4081 & 0.26 & 4.16 & 0.90 & $953 \times 10^{-6}$ & 4.05 & $\mathrm{Y}$ \\
$100 \times 50 \times 3-\mathrm{Mj}$ & 1300 & 600 & 1217 & 0.49 & 8.23 & 0.95 & $39 \times 10^{-6}$ & 0.33 & $\mathrm{Y}$ \\
$100 \times 50 \times 3-\mathrm{Mn}$ & 900 & 300 & 342 & 0.94 & 4.12 & 0.79 & $164 \times 10^{-6}$ & 0.78 & $\mathrm{LB}$ \\
$100 \times 50 \times 6-\mathrm{Mj}$ & 1300 & 600 & 5292 & 0.23 & 17.15 & 1.00 & $270 \times 10^{-6}$ & 2.22 & $\mathrm{Y}$ \\
$100 \times 50 \times 6-\mathrm{Mn}$ & 900 & 300 & 1492 & 0.46 & 8.79 & 0.87 & - & - & $\mathrm{LB}$ \\
\hline
\end{tabular}

Figure 5 plots the recorded experimental moment $\mathrm{M}$ normalised by the plastic moment resistance $\mathrm{M}_{\mathrm{p}}$ against the displacement at midspan for all eight experiments. The specimens failed by either local buckling (LB) or yielding (Y) as reported in Table 4. A graphical representation of the failure modes observed in specimens $100 \times 50 \times 3-\mathrm{Mj}$ and $100 \times 50 \times 3-\mathrm{Mn}$ is shown in Figure 6. 


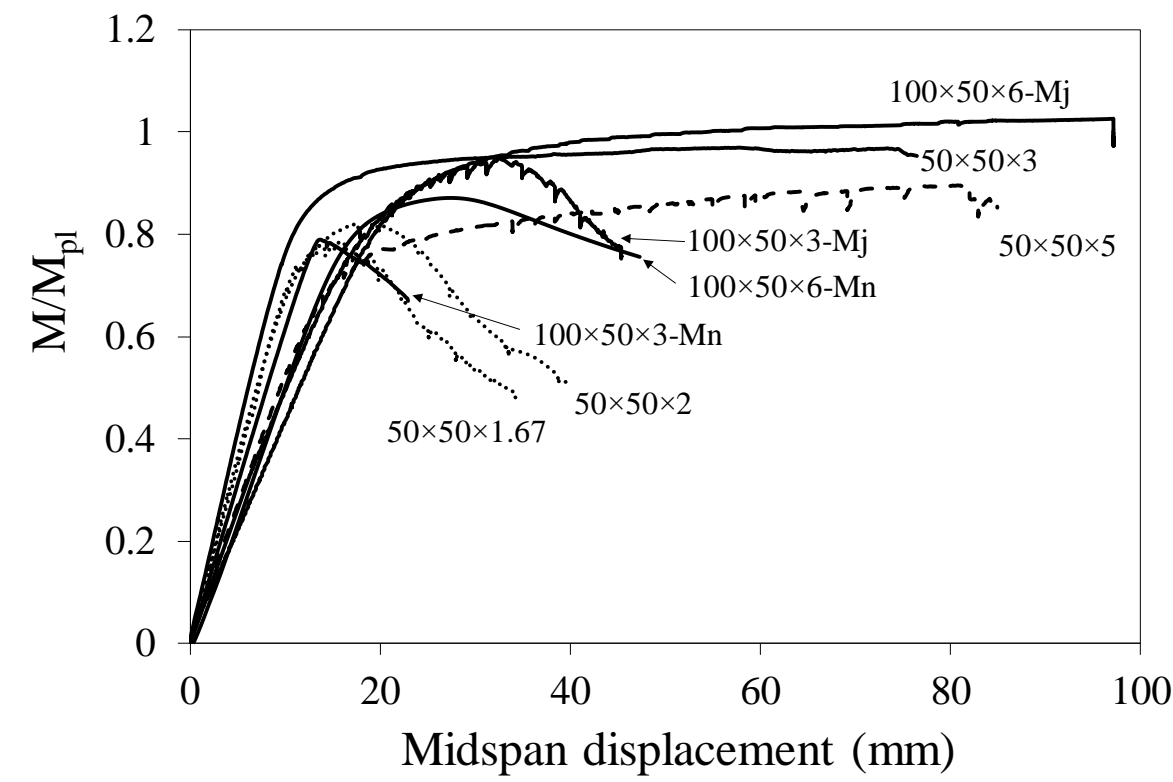

Figure 5 Normalised moment displacement curves for the uniaxial tests
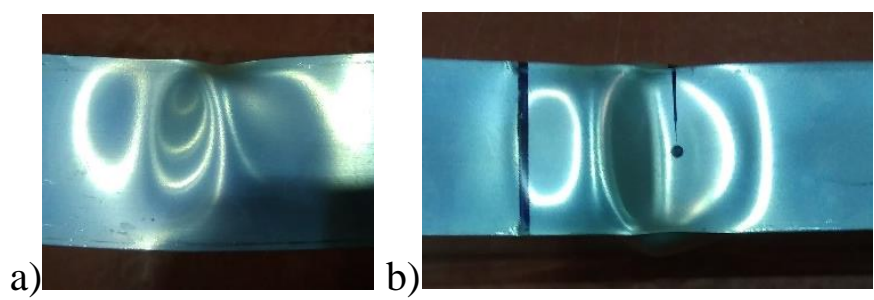

Figure 6 Failure mode $(\mathrm{FM})$ of specimen a) $100 \times 50 \times 3-\mathrm{Mj}$ and b) $100 \times 50 \times 3-\mathrm{Mn}$

\subsection{Biaxial bending tests}

The testing method and instrumentation used for the biaxial bending tests was the same as that used in the uniaxial bending tests as shown in Figure 7. The biaxial bending was achieved through the usage of $\mathrm{V}$-shaped steel plates in the support areas and loading points as detailed in Figure 8 that rotated the specimen by 45 degrees. The distance between the points of loading and supports $\mathrm{L}_{0}$ was $300 \mathrm{~mm}$ and $550 \mathrm{~mm}$ in the tests on SHS and RHS, respectively. Three strain gauges were used in each biaxial bending tests affixed closed to the top, bottom and front corners of the cross-section as shown in Figure 12. The distance apart of the LVDTs placed under the loading points was $300 \mathrm{~mm}$ in all the tests. A total of six biaxial bending tests were carried out. 


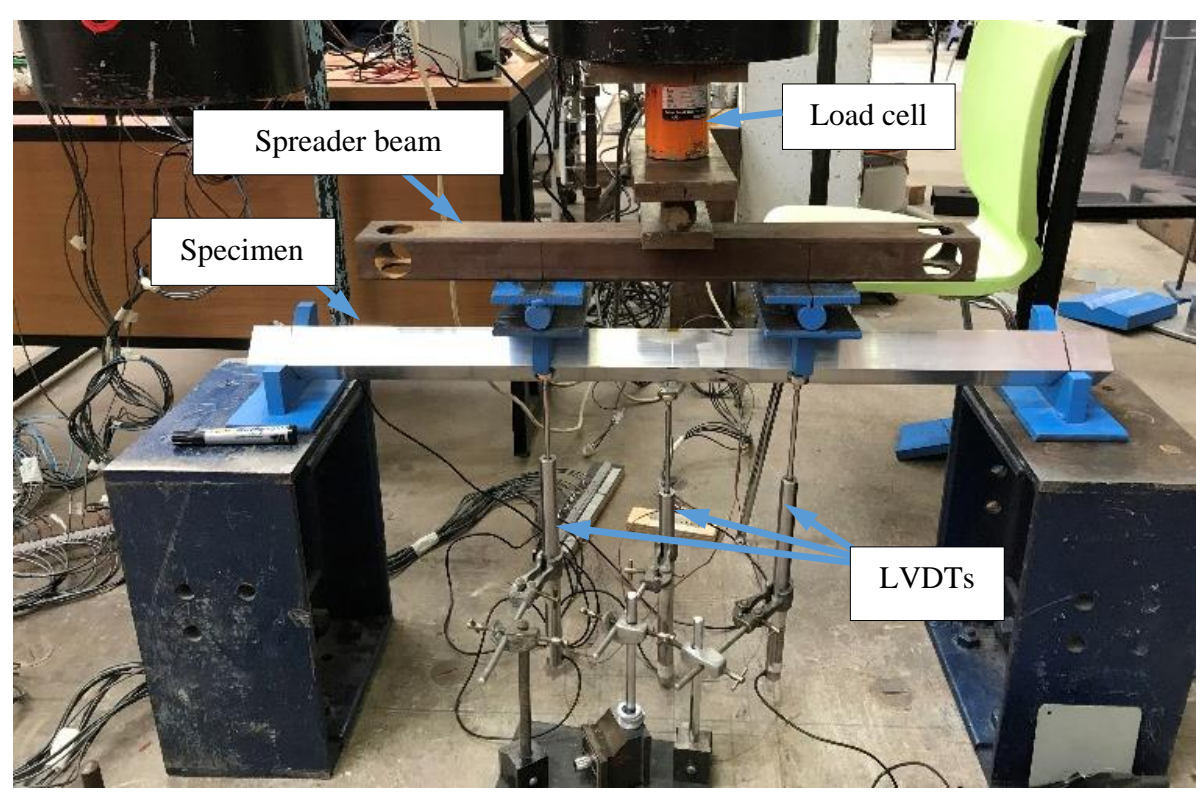

Figure 7 Experimental set up and instrumentation of the biaxial bending tests

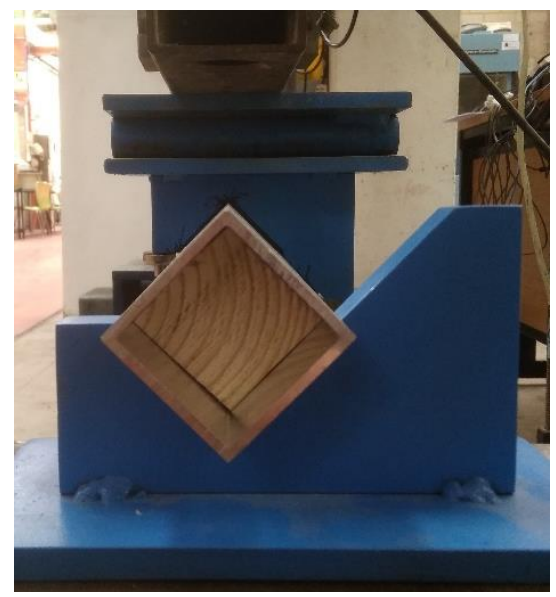

Figure 8 Plate arrangement of the support and loading point

The logged data was used to draw the graph shown in Figure 9 which shows the experimental moment $\mathrm{M}$ normalised by the plastic moment resistance $\mathrm{M}_{\mathrm{p}}$ plotted against the displacement at midspan for all six experiments. The $\mathrm{M}_{\mathrm{p}}$ of the rotated sections was determined by using numerical integration. A tool for this purpose able to calculate the plastic section modulus $\mathrm{W}_{\mathrm{pl}}$ of the rotated sections was developed.

Key experimental results are presented in Table 5 including the ultimate applied force $\mathrm{F}_{\mathrm{u} \text {,exp }}$ and associated bending moment $\mathrm{M}_{\mathrm{u} \text {,exp }}$, the $\mathrm{M}_{\mathrm{u} \text { exp }} / \mathrm{M}_{\mathrm{pl}}$ ratio, the curvatures $\kappa_{\mathrm{u} \text {,exp }}$ and $\kappa_{\mathrm{pl}}$, and the failure modes (FM). The table also includes the slenderness $\bar{\lambda}_{p}$ which was found by using the elastic buckling stress $\sigma_{\text {cr }}$ obtained from the software package CUFSM [34]. The specimens failed by either yielding (Y) or local buckling (LB) of the most heavily stressed cross-sectional corner with the former failure mode (FM) observed in the stockiest specimens. The six failed beams are depicted in Figure 10. 
Table 5 Results of the biaxial bending tests

\begin{tabular}{lccccccccc}
\hline Specimen & $\begin{array}{c}\text { Span } \\
(\mathrm{mm})\end{array}$ & $\begin{array}{c}\mathrm{L} 0 \\
(\mathrm{~mm})\end{array}$ & $\begin{array}{c}\sigma_{\mathrm{cr}} \\
(\mathrm{MPa})\end{array}$ & $\bar{\lambda}_{p}$ & $\begin{array}{c}\mathrm{M}_{\mathrm{u}, \exp } \\
(\mathrm{KNm})\end{array}$ & $\begin{array}{c}\mathrm{M}_{\mathrm{u}, \exp } / \\
\mathrm{M}_{\mathrm{pl}}\end{array}$ & $\begin{array}{c}\kappa_{\mathrm{u}, \exp } \\
\left(\mathrm{mm}^{-1}\right)\end{array}$ & $\begin{array}{c}\kappa_{\mathrm{u}, \exp } / \\
\kappa_{\mathrm{pl}}\end{array}$ & $\mathrm{FM}$ \\
\hline $50 \times 50 \times 1.64$ & 900 & 300 & 647 & 0.57 & 1.15 & 0.99 & $120 \times 10^{-6}$ & 0.84 & $\mathrm{LB}$ \\
$50 \times 50 \times 2$ & 900 & 300 & 971 & 0.46 & 1.30 & 0.95 & $351 \times 10^{-6}$ & 2.52 & $\mathrm{LB}$ \\
$50 \times 50 \times 3$ & 900 & 300 & 2297 & 0.30 & 1.80 & 0.97 & $784 \times 10^{-6}$ & 5.94 & $\mathrm{Y}$ \\
$50 \times 50 \times 5$ & 900 & 300 & 6742 & 0.20 & 4.02 & 1.03 & $1203 \times 10^{-6}$ & 6.15 & $\mathrm{Y}$ \\
$100 \times 50 \times 3$ & 1300 & 550 & 890 & 0.58 & 5.16 & 0.78 & $25 \times 10^{-6}$ & 0.18 & $\mathrm{LB}$ \\
$100 \times 50 \times 6$ & 1300 & 550 & 3834 & 0.28 & 12.6 & 1.07 & $377 \times 10^{-6}$ & 2.91 & $\mathrm{LB}$ \\
\hline
\end{tabular}

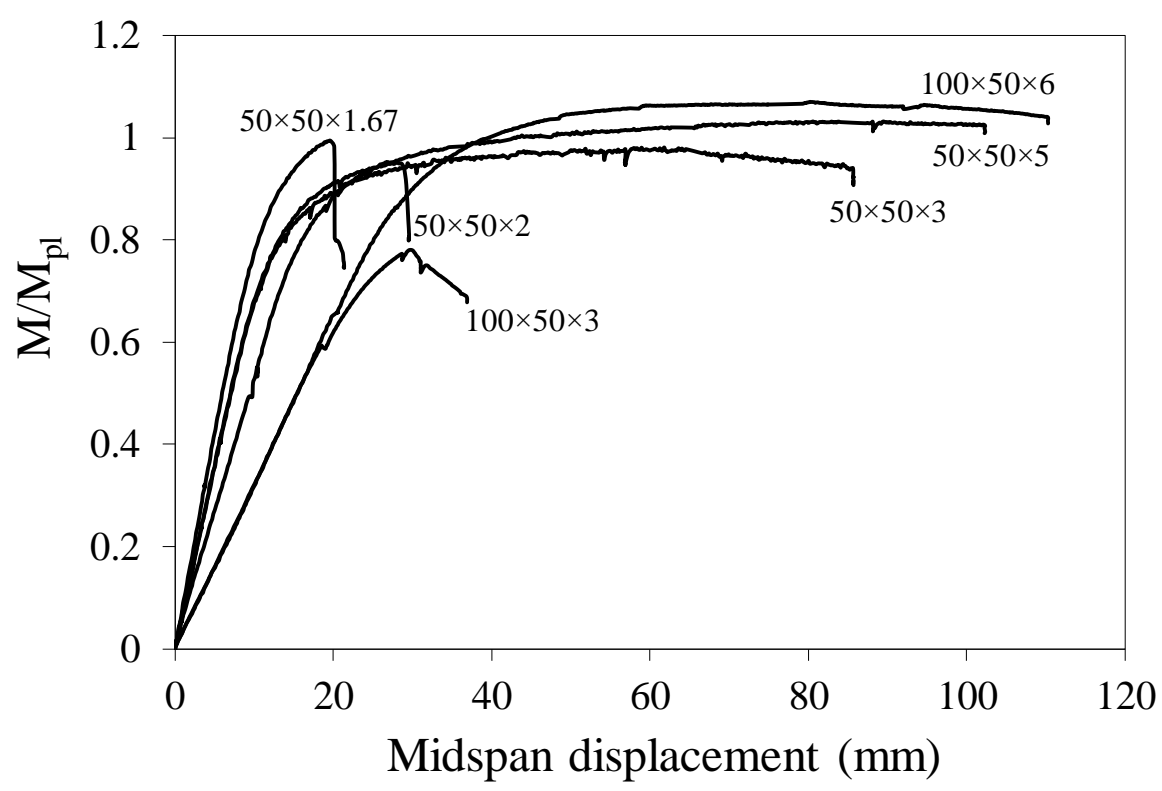

Figure 9 Normalised moment displacement curves for the biaxial bending tests

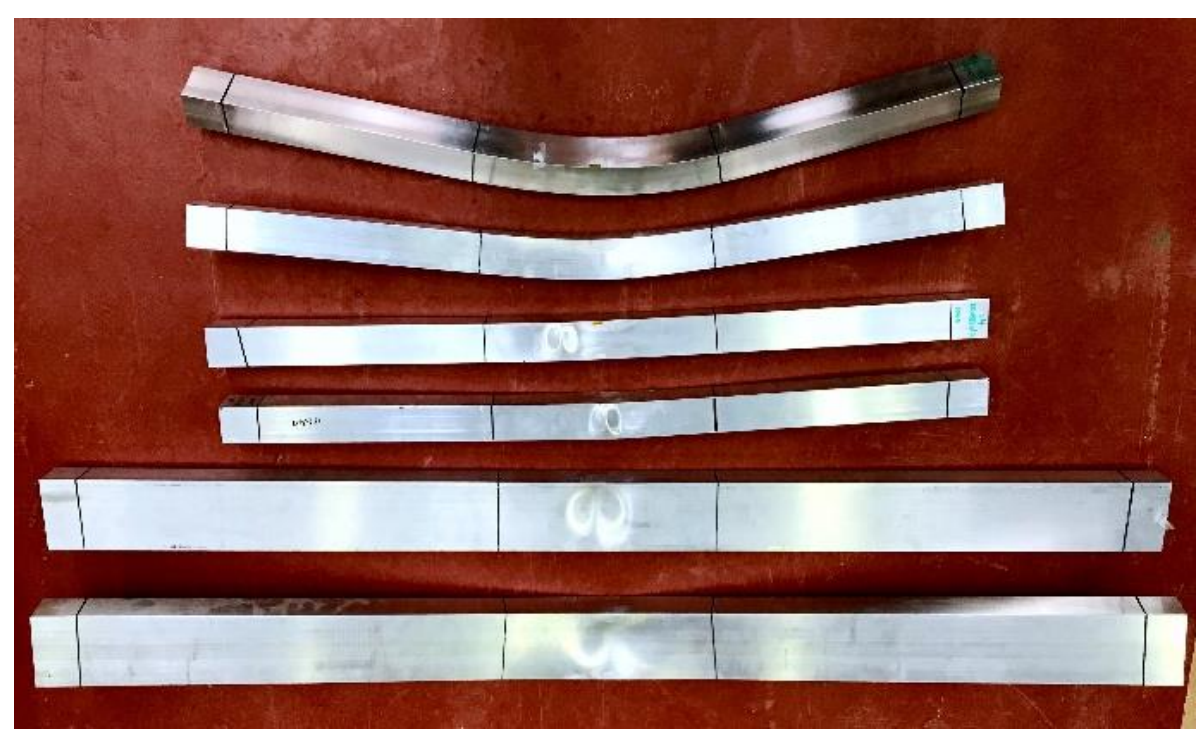

Figure 10 Failed beams subjected to biaxial bending 


\section{$3 \quad$ Numerical modelling}

\subsection{Description of the model}

Having tested extruded aluminium specimens subjected to the fundamental cases of major and minor bending as well as biaxial bending, a numerical model using the general purpose finite element (FE) software ABAQUS [44] was developed.

For the development of the FE models, the four-nodded shell element S4R with reduced integration and finite membrane strains has been adopted which is a type of element that has been widely and successfully used in similar applications $[45,46]$. The modelled geometry was based on the centreline dimensions $h \times b \times t$ shown in Figure 1 by the dash line. The full geometry between supports was modelled. A mesh convergence study was carried out to determine a suitable element size whilst minimising computational time. A size element approximately equal to the plate thickness was selected to discretise the geometry of the aluminium tubes. The models were rotated about its longitudinal axis accordingly.

The obtained material coupon stress-strain curves reported in Table 2, were converted into true stress and logarithmic plastic strain and incorporated into the FE model. For sections where more than one coupon test was performed, average values were used. A Poisson's ratio value of 0.33 was used. In line with past studies [40,45-48] residual stresses were not explicitly modelled.

The supports and loading points were modelled using distributed [40] and kinematic coupling respectively. At both supports and loading points, the six degrees of freedom were constrained with respect to a reference point defined at the centre of gravity of the cross-section which was also used for the application of the boundary conditions and loading. At one of the support points, all degrees of freedom except rotation about the axis of bending were restrained. At the other support point rotation about the axis of bending and translation in the longitudinal direction were allowed whilst all other degrees of freedom were restrained. At the loading points, the lateral displacement was restrained and vertical forces were applied.

\subsection{Validation}

In order to find the ultimate numerical bending resistance $\mathrm{M}_{\mathrm{u}, \mathrm{FE}}$, the models were run in two steps. First, a linear elastic analysis was performed to determine the eigenvalues and buckling modes. The lowest positive buckling mode was subsequently introduced as the initial imperfection shape in the second step which was a static Riks analysis using the default numerical convergence criteria and takes into consideration geometry and material nonlinearities. The impact of various initial imperfection amplitudes including $t / 10, t / 50$ and $t / 100$ was examined. The models were also run without considering imperfections in one step only.

The resulting numerical-to-experimental resistance ratios $\mathrm{M}_{\mathrm{u}, \mathrm{FE}} / \mathrm{M}_{\mathrm{u}, \mathrm{EXP}}$ for the uniaxial and biaxial models are reported in Tables 6 and 7 respectively, while Table 8 reports the mean and coefficient of variation (COV) of all the models together. The results show ratios very close to the unity and relatively small COVs. On this basis, it was therefore deemed that the developed numerical model is reliable and accurate to predict the uniaxial and biaxial behaviour of aluminium SHS and RHS. The accuracy of the models is also depicted in Figures 11 and 12. The former figure shows the moment-midspan displacement where both experimental and 
numerical curves overlap while the latter figure compares the experimental failure of a RHS beam against that predicted by the numerical model.

Table 6 Imperfection sensitivity in the uniaxial models

\begin{tabular}{lcccc}
\hline \multirow{2}{*}{ Specimen } & \multicolumn{4}{c}{$\mathrm{M}_{\mathrm{u}, \mathrm{FE}} / \mathrm{M}_{\mathrm{u}, \mathrm{EXP}}$} \\
& No imp & $\mathrm{t} / 10$ & $\mathrm{t} / 50$ & $\mathrm{t} / 100$ \\
\hline $50 \times 50 \times 1.64$ & 0.99 & 1.00 & 0.99 & 0.99 \\
$50 \times 50 \times 2$ & 1.06 & 1.07 & 1.06 & 1.06 \\
$50 \times 50 \times 3$ & 0.99 & 1.00 & 1.00 & 1.00 \\
$50 \times 50 \times 5$ & 1.05 & 1.04 & 1.05 & 1.05 \\
$100 \times 50 \times 3-\mathrm{Mj}$ & 1.01 & 1.02 & 1.02 & 1.02 \\
$100 \times 50 \times 3-\mathrm{Mn}$ & 1.02 & 1.03 & 1.03 & 1.02 \\
$100 \times 50 \times 6-\mathrm{Mj}$ & 1.07 & 1.02 & 1.06 & 1.06 \\
$100 \times 50 \times 6-\mathrm{Mn}$ & 1.06 & 0.99 & 1.03 & 1.05 \\
\hline \multicolumn{1}{c}{$\mathrm{Mean}$} & 1.03 & 1.02 & 1.03 & 1.03 \\
COV & 0.03 & 0.02 & 0.02 & 0.03 \\
\hline
\end{tabular}

Table 7 Imperfection sensitivity in the biaxial models

\begin{tabular}{ccccc}
\hline \multirow{2}{*}{ Specimen } & & \multicolumn{3}{c}{$\mathrm{M}_{\mathrm{u}, \mathrm{FE}} / \mathrm{M}_{\mathrm{u}, \mathrm{EXP}}$} \\
& No imp & $\mathrm{t} / 10$ & $\mathrm{t} / 50$ & $\mathrm{t} / 100$ \\
\hline $50 \times 50 \times 1.64$ & 0.99 & 0.82 & 0.91 & 0.92 \\
$50 \times 50 \times 2$ & 1.06 & 0.93 & 1.02 & 1.03 \\
$50 \times 50 \times 3$ & 1.06 & 1.02 & 1.06 & 1.06 \\
$50 \times 50 \times 5$ & 1.01 & 0.99 & 1.01 & 1.01 \\
$100 \times 50 \times 3$ & 1.10 & 0.98 & 1.05 & 1.05 \\
$100 \times 50 \times 6$ & 0.98 & 0.94 & 0.97 & 0.98 \\
\hline Mean & 1.03 & 0.95 & 1.00 & 1.01 \\
COV & 0.046 & 0.073 & 0.054 & 0.054 \\
\hline
\end{tabular}

Table 8 Imperfection sensitivity for all models

\begin{tabular}{ccccc}
\hline \multirow{2}{*}{ Specimen } & & \multicolumn{3}{c}{$\mathrm{M}_{\mathrm{u}, \mathrm{FE}} / \mathrm{M}_{\mathrm{u}, \mathrm{EXP}}$} \\
& No imp & $\mathrm{t} / 10$ & $\mathrm{t} / 50$ & $\mathrm{t} / 100$ \\
\hline Mean & 1.03 & 0.99 & 1.02 & 1.02 \\
COV & 0.036 & 0.060 & 0.040 & 0.040 \\
\hline
\end{tabular}




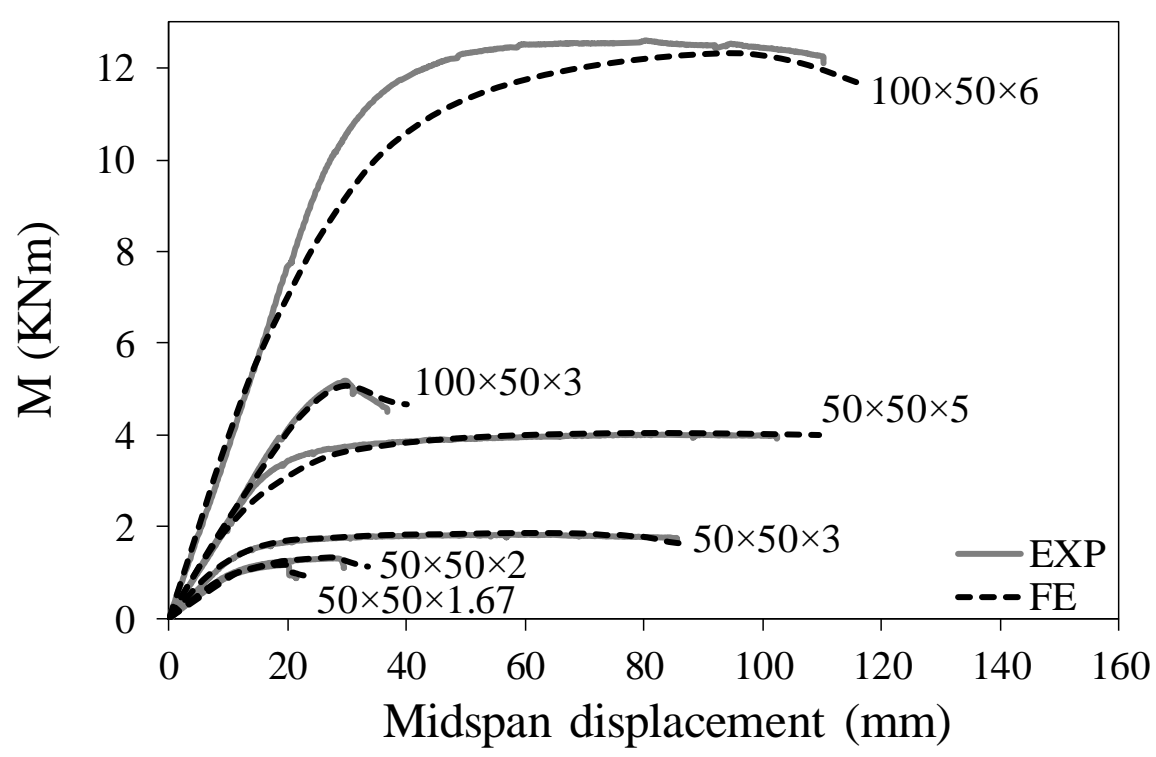

Figure 11 Moment-midspan deflection response for all biaxial models
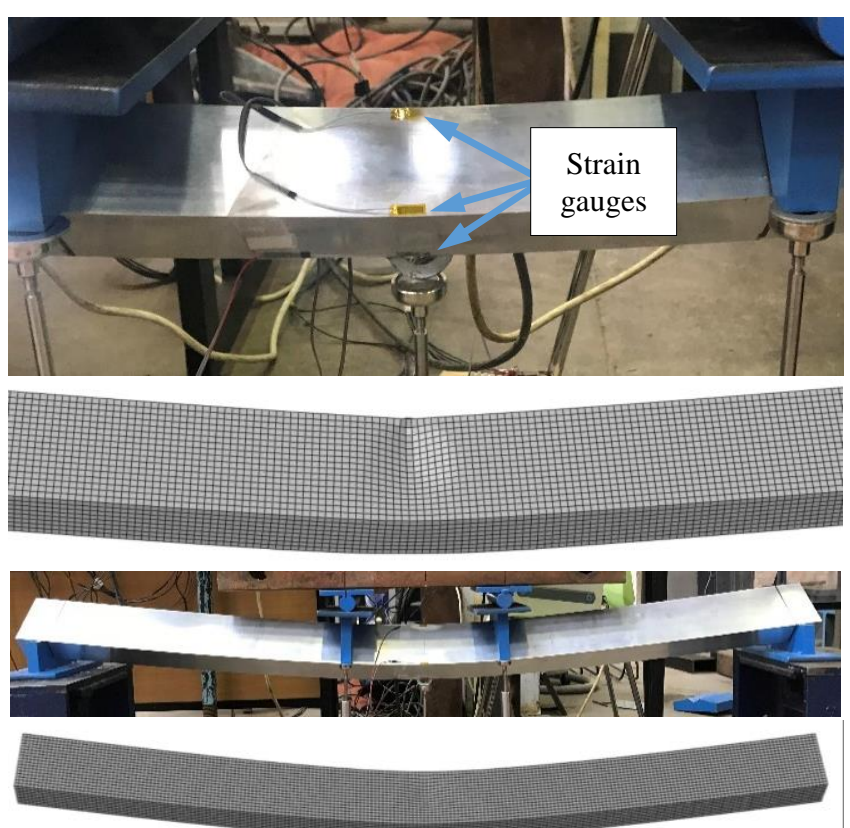

Figure 12 Predicted and experimental failure of the RHS $100 \times 50 \times 3$ subjected to biaxial bending and detail of the strain gauges

\subsection{Parametric studies}

Having validated the numerical model, parametric studies were carried out to explore the impact of more cross-section sizes on the biaxial bending response. Building on centreline dimensions, the parametric study considered SHS 50×50 and RHS 100×50 with thicknesses of $1.67,2,3,4,5$ and $2,3,4,5$ and $6 \mathrm{~mm}$ respectively. With respect to the major axis of the crosssection $y-y$, which was deemed the zero degrees axis, biaxial bending was examined for the rotation $\theta$ values of 15, 30, 45, 60, 75 and 90 degrees, see Figure 13. 


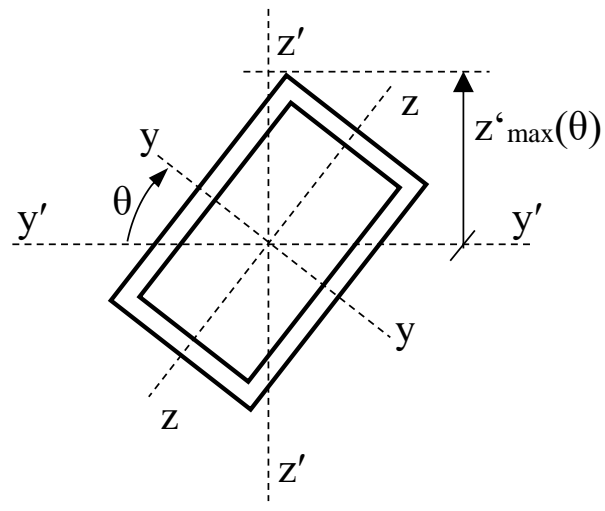

Figure 13 Definition of axis of the rotated section

The material properties reported in Table 3 were used in the parametric study which considered two materials. The first material (alloy 6082T6) was given the properties reported for the $100 \times 50 \times 3-1$ coupon. The second material (alloy 6060) was given the average values of the properties reported for the $50 \times 50 \times 3-1$ and $50 \times 50 \times 3-2$ coupons. Note that based on the ultimate strains $\varepsilon_{u}$ achieved by the coupons, EN 1999-1-1 classifies the first material as ductile and the second material as brittle.

The imperfection amplitude used in the parametric study was t/50. A total of 140 models were generated covering a wide range of slenderness and cross-section classes, the results of which are presented and analysed in the following section.

\section{Results and assessment of design methods}

The results of the parametric study are presented in this section and compared against the design provisions for biaxial bending design given in EN 1999-1-1 [1], the CSM and a design method proposed herein and outlined in this section. To this end, the ultimate numerical bending resistances for the major and minor axis bending were obtained as $\mathrm{M}_{\mathrm{y}, \mathrm{FE}}=\mathrm{Mu}_{\mathrm{u}} \mathrm{FE} \cos \theta$ and $\mathrm{Mz}, \mathrm{FE}=\mathrm{M}_{\mathrm{u}, \mathrm{FESin}} \theta$, respectively. All partial safety factor were set to one. Further details follow in the below sub-sections.

\subsection{Comparison with EN 1999-1-1 [1]}

For the comparison of the numerical results and EN 1999-1-1 [1] the interaction graphs depicted in Figures 14 to 17 are used. These graphs present the ratio $\mathrm{M}_{\mathrm{y}, \mathrm{FE}} / \mathrm{M}_{\mathrm{y}, \mathrm{EC} 9}$ plotted against the ratio $\mathrm{M}_{\mathrm{y}, \mathrm{FE}} / \mathrm{M}_{\mathrm{Z}, \mathrm{EC} 9}$ and the EN 1999-1-1 [1] bending moment interaction curve given by Eq. (3) which is labelled as EC9. $\mathrm{M}_{\mathrm{y}, \mathrm{EC} 9}$ and $\mathrm{M}_{\mathrm{z}, \mathrm{EC} 9}$ are the predicted bending resistance values by EN 1999-1-1 [1] as given by Eqs $(6,7)$. These values were found with and without considering the material strain hardening. Therefore, shape factors $\alpha_{10}$ and $\alpha_{5}$, were used to account for the material strain hardening in alloys $6082 \mathrm{~T} 6$ and 6060, respectively. Figures 1417 place emphasis on the material as well as the cross-section shape.

The results show that as expected the SHS display symmetry with respect to a line passing through the origin with a 45 degree slope as opposed to the RHS. It is also observed that the predictions for SHS fall closer to the EC9 interaction curve than the predictions for the RHS. 
This is attributed to element interaction effects namely for minor axis bending where the shorter faces of the RHS provide a more efficient restrain to the longer faces compared to the restrained offered by the longer faces to the shorter faces under major axis bending. The results also show that due to having greater yield strength $\mathrm{f}_{0}$, alloy $6082 \mathrm{~T} 6$ exhibits greater capacities and consequently, the data lays further from the EC9 interaction curve. However, when material strain hardening is considered, closer to the interaction curve the data is observed. Noting that all data points fall outside the EC9 interaction curve, EN 1999-1-1 is therefore deemed safe yet conservative.

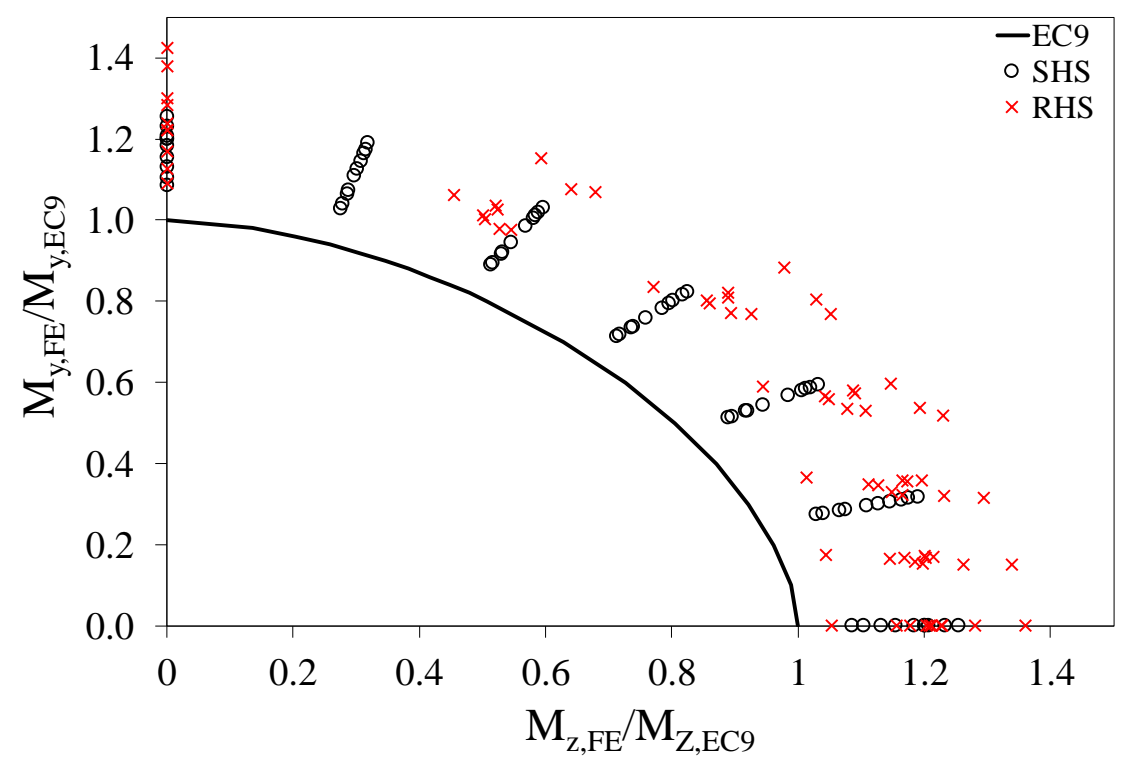

Figure 14 Assessment of EN 1999-1-1 without strain hardening highlighting the crosssectional shape

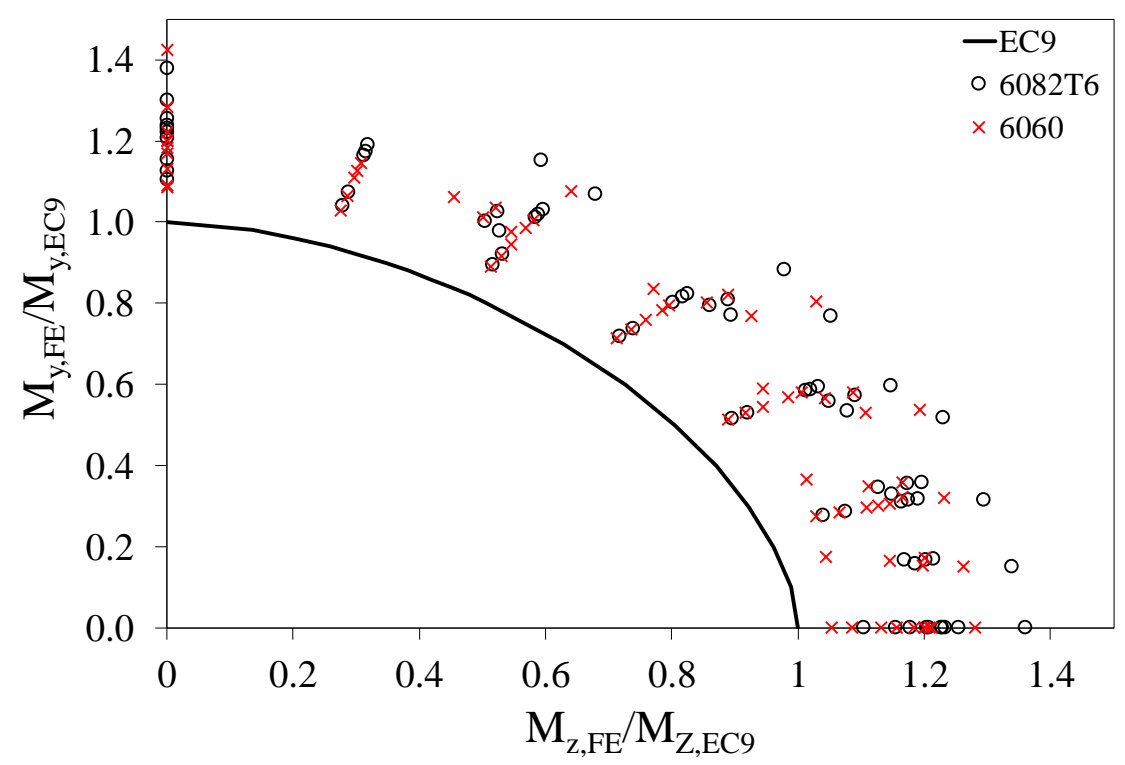

Figure 15 Assessment of EN 1999-1-1 without strain hardening highlighting the material 


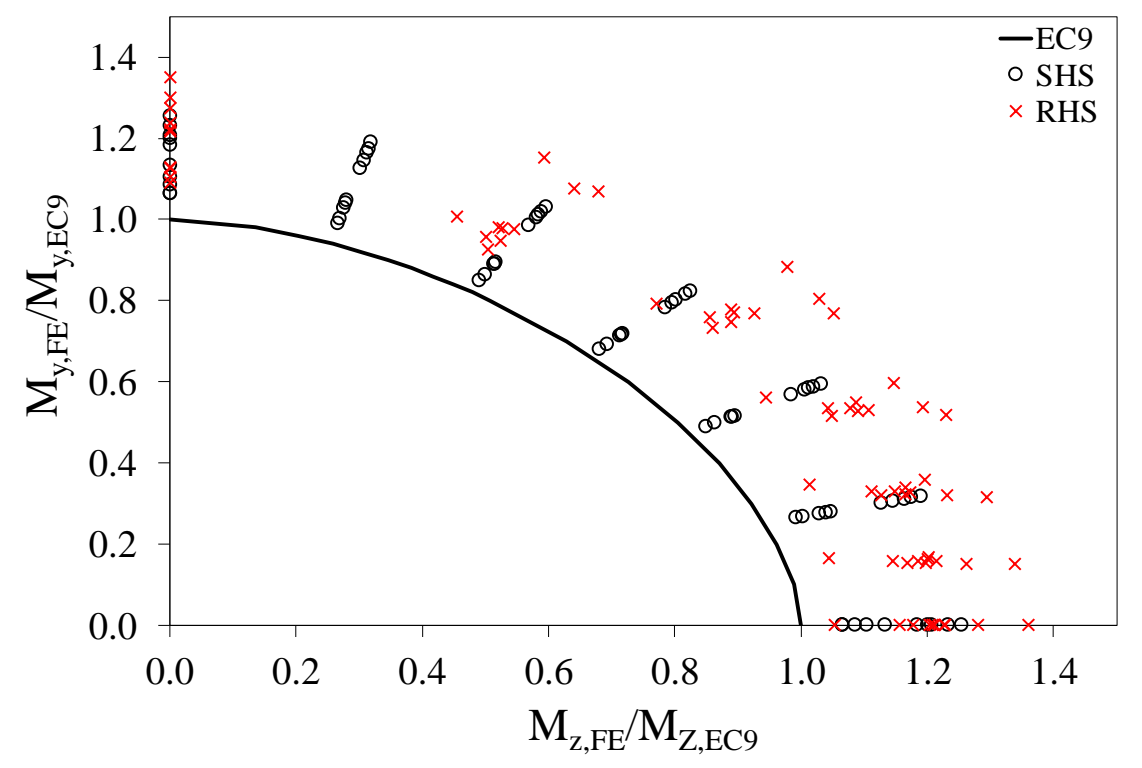

Figure 16 Assessment of EN 1999-1-1 with strain hardening highlighting the cross-sectional shape

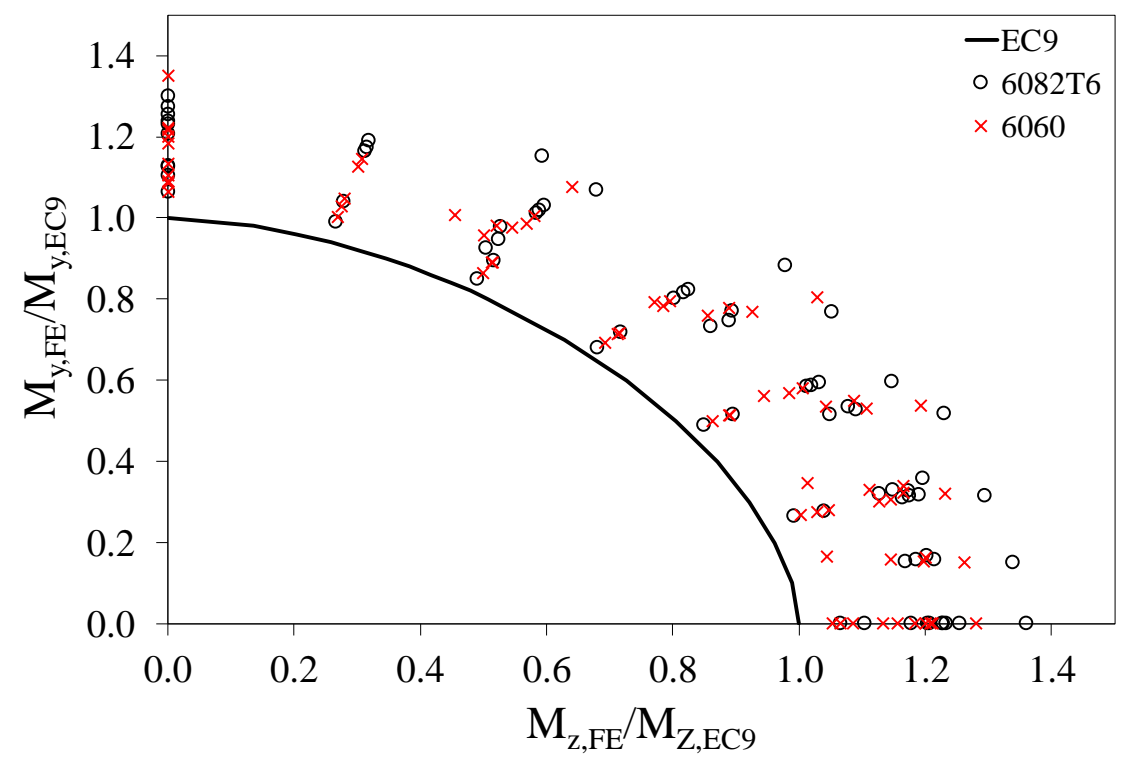

Figure 17 Assessment of EN 1999-1-1 with strain hardening highlighting the material

\subsection{Comparison with the CSM}

For the comparison of the numerical results and the CSM, the interaction graphs depicted in Figures 18 and 19 are used. These graphs present the ratio $\mathrm{M}_{\mathrm{y}, \mathrm{FE}} / \mathrm{M}_{\mathrm{y}, \mathrm{CSM}}$ plotted against the ratio $\mathrm{M}_{\mathrm{y}, \mathrm{FE}} / \mathrm{M}_{\mathrm{z}, \mathrm{CSM}}$ and the EN 1999-1-1 [1] bending moment interaction curve given by $\mathrm{Eq}$. (3) which is labelled as EC9. $\mathrm{M}_{\mathrm{y}, \mathrm{CSM}}$ and $\mathrm{M}_{\mathrm{z}, \mathrm{CSM}}$ are the bending resistance values about the major and minor axis bending, respectively, predicted by the CSM as given by Eqs $(14,15)$. The determination of the strain hardening slope $\mathrm{E}_{\text {sh }}$, see Eq. (17), was conducted by using the revised predictive model for $\varepsilon_{\mathrm{u}}$ proposed in [38] and given in Eq. (18). The slenderness of the cross-section was found by using the elastic critical moment $M_{c r}$ obtained with the CUFSM 
software. In the comparison with the CSM, only stocky sections with $\bar{\lambda}_{p, y}$ and $\bar{\lambda}_{p, z}$ smaller or equal to 0.68 were considered. A total number of 49 SHS and 35 RHS met this requirement.

The comparison shows that the data falls on both sides of the interaction curve and is significantly less scattered than that exhibited by EN 1999-1-1 [1].

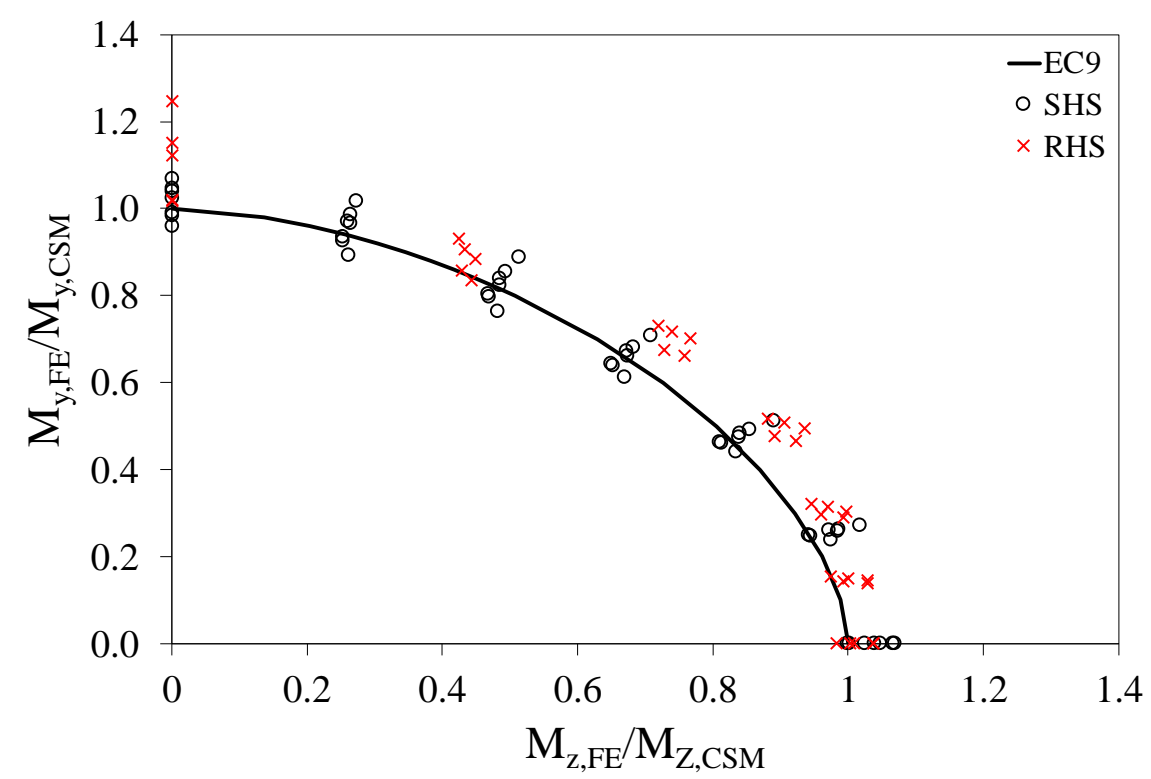

Figure 18 Assessment of the CSM highlighting the cross-sectional shape

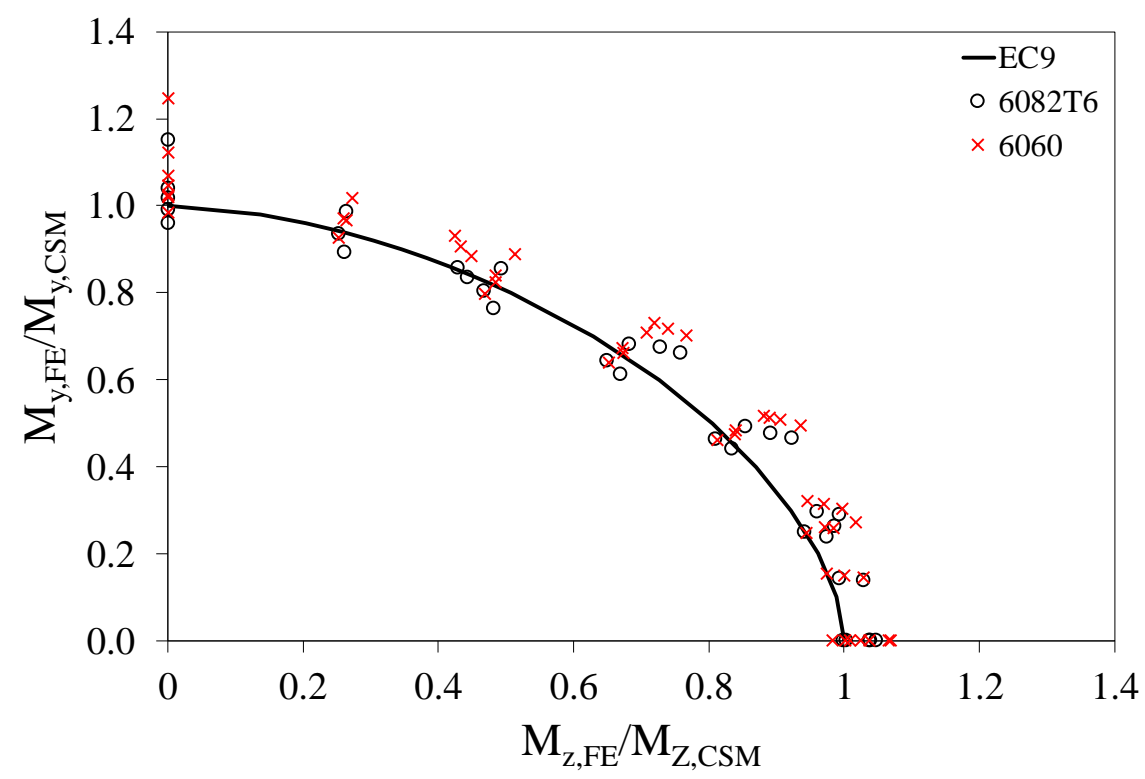

Figure 19 Assessment of the CSM highlighting the material

\subsection{Comparison with the proposed method}

The previously discussed design methods are based on the determination of the moment capacities about the major and minor axes according to EN 1999-1-1 [1] and the CSM which are needed for the application of the interaction equation specified in EN 1999-1-1 [1] to 
account for biaxial bending. An alternative approach, which eliminates the need for an interaction equation is proposed and its performance assessed herein. The proposed method for biaxial bending design consists of the direct application of the CSM design equations considering the cross-sectional properties of the rotated cross-section (i.e. the elastic and plastic section moduli) with respect to the horizontal $y^{\prime}-y^{\prime}$ axis shown in Fig. 13. The proposed method therefore, requires discretizing the rotated cross-section and applying numerical integration. The critical moment $\mathrm{M}_{\mathrm{cr}}$ of the rotated cross-section can be obtained with the CUFSM software to ultimately find the cross-sectional slenderness of the rotated cross-section $\bar{\lambda}_{p}$.

The numerical results obtained from the parametric study were used to assess how biaxial bending data compares against the CSM base curve given by Eq. 14. This comparison is shown in Figure 20 where the numerical normalised deformation capacity $\varepsilon_{\mathrm{csm}} / \varepsilon_{\mathrm{y}}$ is plotted against the cross-sectional slenderness of the rotated cross-section $\bar{\lambda}_{p}$. The $\varepsilon_{\mathrm{csm}} / \varepsilon_{\mathrm{y}}$ was obtained as given by Eq. (23) [27] where $\kappa_{u}$ is the curvature at the ultimate bending moment, see Eq. (22), $\kappa_{\mathrm{el}}=\mathrm{Mel} / \mathrm{EI}$ is the elastic curvature and $\mathrm{z}^{\prime} \max (\theta)$ is the outermost point or fibre of the crosssection with respect to the y'-y' axis, see Figure 13. The comparison shows that the numerical biaxial bending data is in good agreement with the CSM curve.

$$
\frac{\varepsilon_{c s m}}{\varepsilon_{y}}=\frac{\kappa_{u} z_{\text {max }}^{\prime}(\theta)-0.002}{\kappa_{e l} z_{\text {max }}^{\prime}(\theta)}
$$

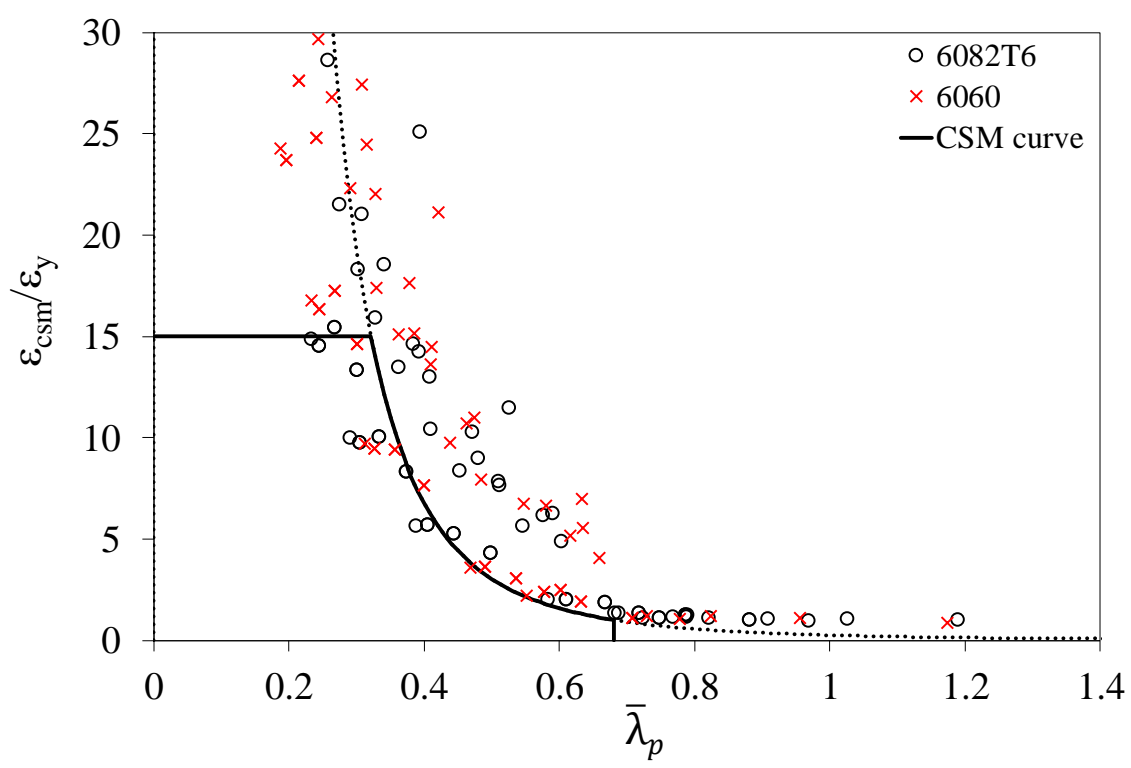

Figure 20 CSM base curve with biaxial bending numerical data

In order to facilitate the utilisation of the proposed method, equations for the elastic and plastic section moduli of the rotated section, $\mathrm{W}_{\mathrm{el}(\theta)}$ and $\mathrm{W}_{\mathrm{pl}(\theta)}$ respectively, were derived analytically. The resulting equations, which are presented in Eqs. (24-27), provided a best fit to numerical data generated with a tool that performs numerical integration of general quantities over a rotated cross-section with certain angle $\theta$ including $\mathrm{Wel}_{\mathrm{el}(\theta)}, \mathrm{W}_{\mathrm{pl}(\theta)}$, second moment of area $\mathrm{I}(\theta)$ as well as any stress distribution over the cross-section considering the outermost crosssectional point or fibre $z^{\prime}{ }_{\max }(\theta)$, see Figure 13. In Eq. (25), $I_{y}$ and $I_{z}$ are the second moment of area about the principal $y-y$ and $z-z$ axes, respectively. Note that overall dimensions must be 
considered in Eqs. (24-26) while centreline dimensions are used in Eq, (27), see Figure 1. Once, $\mathrm{W}_{\mathrm{el}(\theta)}$ and $\mathrm{W}_{\mathrm{pl}(\theta)}$ are obtained and the CSM models for the deformation capacity and material applied, see Eqs (14-18), the bending resistance of the rotated cross-section $\mathbf{M}_{\mathrm{csm}(\theta)}$ can be ultimately found as given by Eq. (28).

$$
\begin{aligned}
& W_{e l(\theta)}=\frac{I(\theta)}{z_{\max }(\theta)} \\
& I(\theta)=\frac{1}{2}\left(I_{y}+I_{z}\right)+\frac{1}{2}\left(I_{y}-I_{z}\right) \cos (2 \theta) \\
& z_{\text {max }}^{\prime}(\theta)=\frac{B}{2} \sin \theta+\frac{H}{2} \cos \theta \\
& W_{p l(\theta)}=\left\{\begin{array}{cl}
{\left[b h \cos \theta+\frac{h^{2}}{2} \cos \theta+\frac{b^{2}}{2} \sin \theta \tan \theta\right] t} & \text { if } \tan \theta<\frac{h}{b} \\
{\left[b h \sin \theta+\frac{b^{2}}{2} \sin \theta+\frac{h^{2}}{2} \frac{\cos \theta}{\tan \theta}\right] t} & \text { if } \tan \theta>\frac{h}{b}
\end{array}\right. \\
& M_{c s m(\theta)}=W_{p l(\theta)} f_{0}\left[1+\frac{E_{s h}}{E} \frac{W_{e l(\theta)}}{W_{p l(\theta)}}\left(\frac{\varepsilon_{c s m}}{\varepsilon_{y}}-1\right)-\left(1-\frac{W_{e l(\theta)}}{W_{p l(\theta)}}\right) /\left(\frac{\varepsilon_{c s m}}{\varepsilon_{y}}\right)^{2}\right]
\end{aligned}
$$

The proposed method is compared against EN 1999-1-1 [1] and the CSM in Figure 21 where the predicted-to-numerical ratio of the ultimate bending moment $\mathrm{M}_{\mathrm{u}, \operatorname{pred}} / \mathrm{M}_{\mathrm{u}, \mathrm{FE}}$ is plotted against the slenderness of the rotated cross-section $\bar{\lambda}_{p}$. The predicted bending moments $\mathrm{Mu}_{\mathrm{u} \text {,pred }}$ by EN 1999-1-1 and the CSM were determined by using the interaction graphs presented in Figures 14-19 measuring the distance from the origin to each data point $|\mathrm{OA}|$, the distance from the origin to the intersection of $|\mathrm{OA}|$ with EC9 interaction curve $|\mathrm{OB}|$ and dividing $|\mathrm{OA}|$ over $|\mathrm{OB}|$. This approach was used in previous investigations dealing with interaction curves $[49,50]$. Material strain hardening was considered in the determination of $\mathrm{M}_{\mathrm{u} \text {,pred }}$ by EN 1999$1-1[1]$.

The comparison shows that EN 1999-1-1 provides the most conservative predictions with predicted-to-numerical ratios around 0.8 while the CSM and the proposed method provide predicted-to-numerical ratios closer to one and therefore are less conservative. The results also show that none of the methods is dependent of $\bar{\lambda}_{p}$. Further assessment of the three methods is carried out in the next section where design recommendations are provided. 


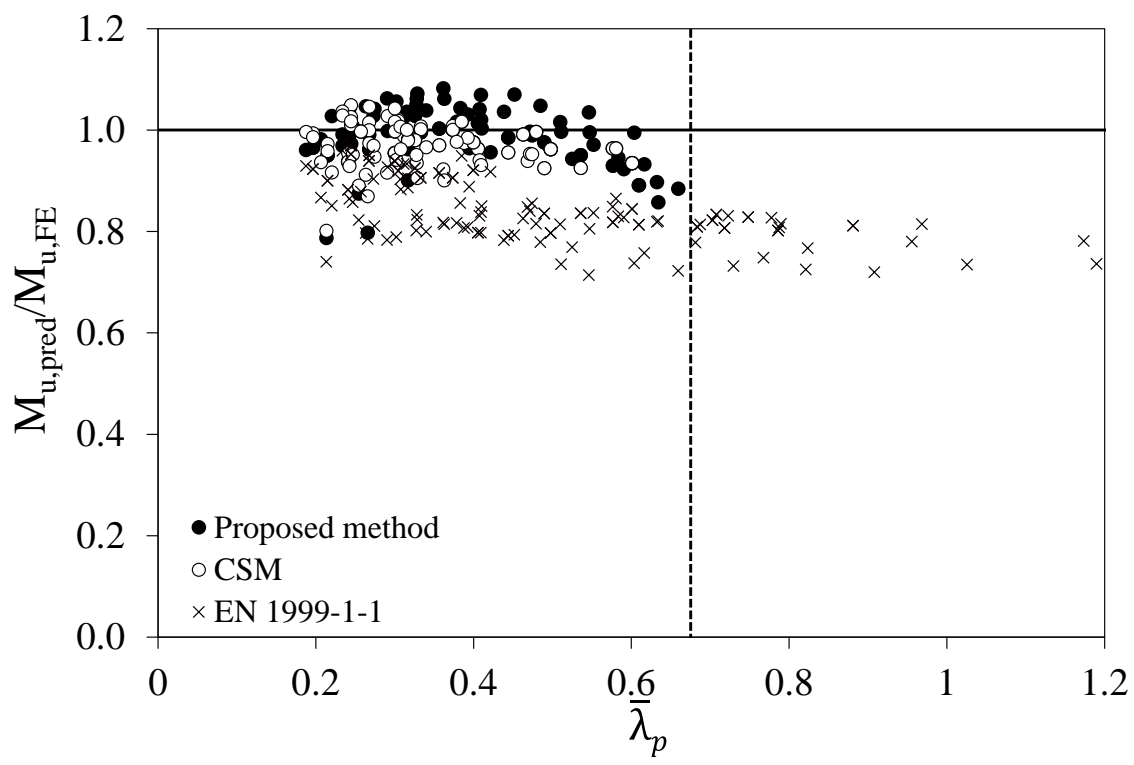

Figure 21 Comparison of the numerical results with EN 1999-1-1 [1], the CSM and the proposed method

\section{Design recommendations for biaxial bending of aluminium alloys}

Design recommendations are given in this section based on the mean values and coefficient of variation $(\mathrm{COV})$ of the predicted-to-numerical ratios for various data sets which are shown in Table 9. The ratios were determined for EN 1999-1-1 [1] without considering strain hardening labelled as EC9 NSH in Table 9, EN 1999-1-1 [1] considering strain hardening labelled as EC9 SH in Table 9, the CSM and the proposed method. The data sets under consideration were SHS only, RHS only, 6060 alloy only, $6082 \mathrm{~T} 6$ alloy only, stocky sections, slender sections and all the sections for which each approach is applicable. The ratios show that EN 1999-1-1 [1] is overly conservative and underestimates biaxial bending capacities by $17 \%$ with relatively low scatter (i.e. COV of 6.5\%). EN 1999-1-1 [1] predictions improve when strain hardening is considered but scatter increases in all sets of data. Both the CSM and proposed methods significantly improve predictions with, on average, underestimations of only $3 \%$ and $1 \%$, respectively. The proposed method shows slightly higher COVs than the CSM which is because the number of data points that could be considered was larger. Yet, the COV of the proposed method when all data is considered is $5.4 \%$ which is acceptable. On this basis it is concluded that both the CSM and the proposed method presented in section 4.3 which employs Eqs. (14-18) and Eqs. (24-28) are alternative methods to EN 1999-1-1 that provide a more efficient and reliable design of biaxial bending of aluminium alloy members.

Table 9 Mean and COV for various data sets and design approaches

\begin{tabular}{llccc}
\hline Data set & Approach & Sample size & Mean & COV \\
\hline SHS & EC9 NSH & 70 & 0.86 & 0.051 \\
& EC9 SH & 70 & 0.87 & 0.068 \\
& CSM & 49 & 0.98 & 0.035 \\
& Proposed method & 55 & 0.98 & 0.032 \\
\hline
\end{tabular}




\begin{tabular}{llccc}
\hline RHS & EC9 NSH & 70 & 0.80 & 0.064 \\
& EC9 SH & 70 & 0.81 & 0.067 \\
& CSM & 35 & 0.95 & 0.046 \\
& Proposed method & 54 & 1.00 & 0.067 \\
\hline 6060 alloy & EC9 NSH & 70 & 0.84 & 0.063 \\
& EC9 SH & 70 & 0.86 & 0.078 \\
& CSM & 35 & 0.96 & 0.044 \\
& Proposed method & 61 & 0.98 & 0.054 \\
\hline 6082T6 alloy & EC9 NSH & 70 & 0.82 & 0.065 \\
& EC9 SH & 70 & 0.83 & 0.079 \\
& CSM & 49 & 0.98 & 0.040 \\
& Proposed method & 48 & 0.99 & 0.053 \\
\hline Stocky & EC9 NSH & 84 & 0.85 & 0.051 \\
& EC9 SH & 84 & 0.87 & 0.058 \\
\hline Slender & EC9 NSH & 56 & 0.80 & 0.042 \\
\hline All & EC9 NSH & 140 & 0.83 & 0.065 \\
& EC9 SH & 140 & 0.84 & 0.079 \\
& CSM & 85 & 0.97 & 0.044 \\
& Proposed method & 116 & 0.99 & 0.054 \\
\hline
\end{tabular}

\section{Conclusions}

The research presented in this article has reported experiments on aluminium alloy SHS and RHS subjected to the fundamental cases of bending about the major and minor axis as well as biaxial bending. A test set up for biaxial bending has been presented which, to the authors' knowledge, has never been utilised before. Biaxial bending was achieved through the utilisation of V-shaped supports, which rotated the cross-section placed under the specimens and between the specimens and loading points. The experimental results were used to calibrate a numerical model to subsequently undertake parametric studies and generate biaxial bending behaviour data. Seven angles of rotation, five different thicknesses and two aluminium alloys namely $6082 \mathrm{~T} 6$ and 6060 made up the 140 numerical models split into 70 SHS and 70 RHS. The numerical results were used to plot interaction graphs and compare the design provisions for biaxial bending with and without considering material strain hardening given in EN 19991-1 [1] with the predictions by the CSM and a new proposed approach that directly computes the resistance of sections subjected to biaxial bending without the need for using an interaction curve equation. The proposed approach utilises the CSM base curve and material model given by Eqs. (14-18) but utilises the rotated cross-sectional properties as derived in Eqs. (24-27) to ultimately compute the bending resistance of the rotated cross-section as given by Eq. (28).

The comparison showed that EN 1999-1-1 [1] is safe but underestimates the biaxial bending resistance by $17 \%$ which is improved by $1 \%$ when the material strain hardening is considered. That conservatism is significantly reduced by both the CSM and the new approach presented in this article to $3 \%$ and $1 \%$, respectively. Therefore, both the CSM and the new approach are recommended as alternative more accurate and reliable procedures than EN 1999-1-1 [1] for the design of tubular aluminium alloy elements subjected to biaxial bending. 


\section{Acknowledgements}

The research presented in this article has received funding from the Early Researcher Award Scheme 2018/19 of the University of Wolverhampton. The authors are also grateful to $\mathrm{Mr}$ David Price technician of the laboratory of the Department of Metallurgy and Materials of the University of Birmingham for his assistance with the material coupon tests.

\section{References}

[1] European Committee for Standardization (2007). Eurocode 9: design of aluminium structures-Part 1-1: general rules-general rules and rules for buildings. Brussels: CEN.

[2] May, J. E.; Menzemer, C. C. (2005) Strength of bolted aluminium alloy tension members. Journal of Structural Engineering (ASCE) 131, 7, 1125-1134.

[3] Langseth , M.; Hopperstad, O.S. (1997) Local buckling of square thin-walled aluminium extrusions. Thin-Walled Structures 27 (1), 117-126.

[4] Hopperstad, O.S.; Langseth , M. (1999) Ultimate strength of aluminium alloy outstands in compression: experiments and simplified analysis. Thin-Walled Structures 34 (4), 279-294.

[5] Faella, C.; Mazzolani, F.M.; Piluso, V.; Rizzano, G. (2003) Local buckling of aluminum members: testing and classification. Journal of Structural Engineering (ASCE) 126 (3), 353-360.

[6] Mazzolani, F.M.; Piluso, V.; Rizzano, G. (2011) Local buckling of aluminum alloy angles under uniform compression. Journal of Structural Engineering (ASCE) 137 (2), 173-184.

[7] Yuan, H.X.; Wang, Y.Q.; Chang, T.; Du, X.X.; Bu, Y.D.; Shi, Y.J. (2015) Local buckling and postbuckling strength of extruded aluminium alloy stub columns with slender Isections. Thin-Walled Structures 90, 140-149.

[8] Feng, R.; Young, B (2015) Experimental investigation of aluminium alloy stub columns with circular openings. Journal of Structural Engineering (ASCE) 141 (11), 04015031.

[9] Feng, R.; Zhu, W.; Wan, H; Chen, A; Chen, Y. (2018) Tests of perforated aluminium alloy SHSs and RHSs under axial compression. Thin-Walled Structures 130, 194-212.

[10] Su, M.N.; Young, B.; Gardner, L. (2014) Testing and design of aluminum alloy cross sections in compression. Journal of Structural Engineering (ASCE) 140 (9), 04014047.

[11] Zhu, J.H.; Young, B. (2006) Experimental investigation of aluminium alloy circular hollow section columns. Engineering Structures 28, 207-215.

[12] Zhu, J.H.; Young, B. (2006) Tests and design of aluminum alloy compression members. Journal of Structural Engineering (ASCE) 132 (7), 1096-1107.

[13] Wang, Y.; Fan, F.; Lin, S. (2015) Experimental investigation on the stability of aluminium alloy 6082 circular tubes in axial compression. Thin-Walled Structures 89, 
54-66.

[14] Zhao, Y.Z.; Zhai, X.M.; Sun, L.J. (2016) Test and design method for the buckling behaviors of 6082-T6 aluminum alloy columns with box-type and L-type sections under eccentric compression. Thin-Walled Structures 100, 62-80.

[15] Wang, Y.Q.; Yuan, H.X.; Chang, T.; Du, X.X.; Yu, M. (2017) Compressive buckling strength of extruded aluminium alloy I-section columns with fixed-pinned end conditions. Thin-Walled structures 119, 396-403.

[16] Liu, M.; Zhang, L.; Wang, P.; Chang, Y. (2015) Buckling behaviors of section aluminum alloy columns under axial compression. Engineering Structures 95, 127-137.

[17] Lai, Y.F.W.; Nethercot, D.A. (1992) Strength of aluminium members containing local transverse welds. Engineering Structures 14 (4), 241-54.

[18] Moen, L.A.; Hopperstad, O.S; Langseth, M. (1999) Rotational capacity of aluminium beams under moment gradient. I: experiments. Journal of Structural Engineering 125 (8), 910-20.

[19] Zhu, J.H.; Young, B. (2006) Experimental investigation of aluminium alloy thin-walled tubular members in combined compression and bending. Journal of Structural Engineering 132 (12), 1955-66.

[20] Zhu, J.H.; Young, B. (2009) Design of aluminium alloy flexural members using direct strength method. Journal of Structural Engineering 135 (5), 558-66.

[21] Su, M.; Young, B.; Gardner, L. (2014) Deformation-based design of aluminium alloy beams. Engineering Structures 80, 339-49.

[22] Su, M.; Young, B.; Gardner, L. (2016) Flexural response of aluminium alloy SHS and RHS with internal Stiffeners. Engineering Structures 121, 170-180.

[23] Su, M.; Young, B; Gardner, L. (2015) Continuous Beams of aluminium alloy tubular cross sections. I: Tests and FE model validation. Journal of Structural Engineering (ASCE) 141 (9), 04014232.

[24] Kim, Y.; Peköz, T. (2018) Numerical Slenderness Approach for design of complex aluminium extrusions subjected to flexural loading. Thin-Walled Structures 127, 62-75.

[25] Lin Pi, Y.; Trahair, N.S. (1994) Inelastic bending and torsion of Steel I-beams. Journal of Structural Engineering (ASCE) 120, 3397-3417.

[26] Gardner, L. (2008) The continuous strength method. Proceedings of the Institution of Civil Engineers-Structures and Buildings 161, 127-33.

[27] Afshan, S.; Gardner, L. (2013) The Continuous Strength Method for structural stainless steel design. Thin-Walled Structures 68, 42-49.

[28] Bock, M.; Gardner, L.; Real, E. (2015) Material and local buckling response of ferritic 
stainless steel sections. Thin-Walled Structures 89, 131-141.

[29] Gardner, L.; Wang, F.; Liew, A. (2011) Influence of strain hardening on the behavior and design of steel structures. International Journal of Structural Stability and Dynamics 11, 855-75.

[30] Liew, A.; Gardner, L. (2015) Ultimate capacity of structural steel cross-sections under compression, bending and combined loading. Structures 1, 2-11.

[31] Su, M,; Young, B.; Gardner, L. (2016) The continuous strength method for the design of aluminium alloy structural elements. Engineering Structures 122, 338-348.

[32] AISC Design Guide 30: Structural Stainless Steel. American Institute of Steel Construction; 2012.

[33] European Committee for Standardization (2005). Eurocode 3: design of steel structures-Part 1-1: general rules-general rules and rules for buildings. Brussels: European Committee for Standardization (CEN).

[34] Schafer, B; Ádány, S. (2006) Buckling analysis of cold-formed steel members using CUFSM: conventional and constrained finite strip methods. The 18th international specialty conference on cold-formed steel structures, p. 39-54.

[35] Seif, M.; Schafer, B.W. (2010) Local buckling of structural steel shapes. Journal of Constructional Steel Research 66 (10), 1232-1247.

[36] Gardner, L.; Fieber, A.; Macorini, L. (2019). Formulae for calculating elastic local buckling stresses of full structural cross-sections. Structures 17, 2-20.

[37] European Committee for Standardization (2005). Eurocode 3: design of steel structures-Part 1-5: Plated structural elements. Brussels: European Committee for Standardization (CEN).

[38] Su, M.; Young, B.; Gardner, L. (2014) Testing and design of aluminium alloy crosssections in compression. Journal of Structural Engineering 140(9):04014047.

[39] EN ISO 6892-1:2016 (2016). Metallic materials - Tensile testing, Part 1: Method of test at room temperature. London: BSI.

[40] Gkantou, M.; Kokosis, G.; Theofanous, M.; Dirar, S. (2019) Plastic design of stainless steel continous beams. Journal of Constructional Steel Research 152, 68-80.

[41] Bock, M.; Arrayago, I.; Real E. (2015) Experiments on cold-formed ferritic stainless steel slender sections. Journal of Constructional Steel Research 109, 13-23.

[42] Theofanous, M.; Gardner, L. (2010) Experimental and numerical studies of lean duplex stainless steel beams. Journal of Constructional Steel Research 66 (6), 816-825.

[43] Rasmussen, K.J.R.; Hancock, G.J. (1993) Design of cold-formed stainless steel tubular members. II: Beams. Journal of Structural Engineering (ASCE) 119 (8), 2368-2386. 
[44] Dassault Systemes (2014) ABAQUS/Standard user's manual volumes I-III and ABAQUS CAE manual - Version 6.19. UK: Simulia Corporation.

[45] Bock, M.; Gkantou, M.; Theofanous, M. (2019) Slenderness limits of aluminium outstand elements subjected to stress gradients. Bradford, UK: 9th International Conference on Steel and aluminium structures (ICSAS 19).

[46] Wang, J.; Afshan, S.; Gkantou, M.; Theofanous, M.; Baniotopoulos, C.; Gardner, L. (2016) Flexural behaviour of hot-finished high strength steel square and rectangular hollow sections. Journal of Constructional Steel Research 121, 97-109.

[47] Castaldo, P.; Nastri, E.; Piluso, V. (2017) Ultimate behaviour of RHS temper T6 aluminium alloy beams subjected to non-uniform bending: Parametric analysis. ThinWalled Structures 115, pp. 129-141.

[48] Castaldo, P.; Nastri, E.; Piluso, V. (2017) FEM simulations and rotation capacity evaluation for RHS temper T4 aluminium alloy beams. Composites Part B: Engineering, 115, pp. 124-137.

[49] Arrayago, I; Picci, F; Mirambell, E; Real, E (2015) Interaction of bending and axial load for ferritic stainless steel RHS columns. Thin-Walled Structures 91, 96-107.

[50] Trahair, N.S (2007) Biaxial bending steel angle section beams. Journal of Structural Engineering (ASCE) 130 (4), 554-561. 